\title{
Dissecting Earnings Recognition Timeliness
}

\author{
RYAN T. BALL* AND PETER EASTON
}

Received 31 March 2011; accepted 20 June 2013

\begin{abstract}
${ }^{*}$ Ross School of Business, University of Michigan; ${ }^{\dagger}$ Center for Accounting Research and Education, University of Notre Dame.

Accepted by Abbie Smith. We thank Ana Albuquerque, Elio Alfonso, Ravi Avram, Brad Badertscher, Ray Ball, Phil Berger, Jeff Burks, Robert Bushman, Jeff Callen, Hans Christensen, Dan Collins, Bill Cready, Christine Cuny, Dain Donelson, Jere Francis, Robert Freeman, Jim Fuehmeyer, Eric Ghysels, Cristi Gleason, Mary Hill, Leslie Hodder, Robert Hogan, Pat Hopkins, Paul Hribar, Wenli Huang, Ross Jennings, Bruce Johnson, Steve Kachelmeier, Inder Kharana, Christian Leuz, Lorie Marsh, Ed Maydew, John McInnis, Brian Miller, Mike Minnis, Partha Mohanram, Steve Monahan, John O'Hanlon, Ken Peasnell, Raynolde Pereira, Jan Pfister, Ram Ramanan, Gord Richardson, Haresh Sapra, Mark Shakleton, Shiva Shivakumar, Kumar Sivakumar, Doug Skinner, Christian Stadler, Tom Stober, Philip Stocken, Xiaoli Tian, Eric Weisbrod, Teri Yohn, Yong Yu, Yong Zhang, two anonymous reviewers, workshop participants at Arizona State University, Boston University, Brock University, Florida International University, Hong Kong Polytechnic University, Indiana University, Lancaster University, London Business School, Louisiana State University Regional Conference, Ohio State University, Pennsylvania State University, Tel Aviv University, Tilburg University, the University of Chicago, the University of Iowa, the University of Miami, the University of Michigan, the University of Missouri, Columbia, the University of North Carolina/Duke University Fall camp, the University of Notre Dame, the University of Texas, and the University of Toronto for helpful comments on earlier drafts of this paper. Ryan Ball gratefully acknowledges financial support from the University of Michigan, the University of Chicago Booth School of Business, and the Neubauer Family Fellowship.
\end{abstract}


in the same period as the related benefits (i.e., sales revenue) accrue; and (2) recognition of expenses in the current period due to changes in expectations regarding earnings of future periods (we refer to these expenses as the expectations element of expenses). Although the expectations element has implicitly been at the core of much of the recent empirical literature on asymmetry in the earnings/return relation, it has not been explicitly identified. This recent literature is based on the premise that bad news about the future leads to more recognition of expenses in the current period (such as write-downs) whereas good news about the future tends to have a much lesser effect on expenses of the current period; asymmetry in the expenses/return relation is captured implicitly via the observation of asymmetry in the earnings/return relation (i.e., asymmetry in ERT). Since the ERT reflects the relation between sales revenue and returns, matched expenses and returns, as well as the relation between the expectations element of expenses and returns, a focus on the expectations element may lead to sharper inferences. Our straightforward empirical procedure permits a focus on this element.

\section{Introduction}

We dissect the portion of stock price change of the fiscal year that is recognized in reported accounting earnings of the fiscal year. We call this portion earnings recognition timeliness (ERT). Our emphasis is on identification of elements of ERT that are the empirical manifestation of two fundamental precepts of financial accounting: (1) the matching principle, which leads to recognition of expenses in the same period as the related benefits (i.e., sales revenue) accrue; and (2) recognition of expenses in the current period due to changes in expectations regarding earnings of future periods (we refer to these expenses as the expectations element of expenses). Although this expectations element has implicitly been at the core of much of the recent empirical literature on the earnings/return relation, it has not been explicitly identified.

Beaver, Lambert, and Morse [1980] and Beaver, Lambert, and Ryan [1987] were the first to focus on ERT as we have defined it. The essence of the model in these papers is that, if the news in price change signals a transitory change in earnings, ERT will be one and, if earnings are permanent, the coefficient will be $r /(1+r)$, where $r$ is the rate for capitalizing the future earnings expectations. Basu [1997] built on this literature, introducing the notion that the accounting for changes in expectations about future earnings may affect expenses in the current period and this accounting effect is asymmetric; bad news about future earnings leads to expenses (e.g., write-downs) but good news has a relatively smaller effect on expenses of the period. Thus, Basu [1997] introduced a third link in addition to: (1) the link between price changes and current earnings, and (2) the link between price changes and changes in expectations of future earnings. The third link is between changes in expectations of future earnings and expenses incurred in the current period due to the changes in these expectations. We identify this third link empirically. 
In the vast literature that follows Basu [1997], asymmetric timely loss recognition is, generally, demonstrated empirically via asymmetry in the earnings/return relation (i.e., asymmetry in ERT). But, ERT reflects the relation between sales revenue and returns, matched expenses and returns, as well as the relation between the expectations element of expenses and returns. Each of these relations may differ across good news (i.e., positive return) and bad news (i.e., negative return) subsamples. Our method, which estimates the relation between the expectations element of expenses and returns, may lead to sharper inferences.

The distinction between matched expenses and the expectations element of expenses serves to bring a clearer empirical focus on the expenses that are at the heart of arguments that asymmetric loss recognition leads to more efficient contracting (i.e., on the one hand, accounting tends to bring forward expenses associated with bad news regarding the future via, for example, write-downs, but, on the other hand, accounting capitalizes expenditures, such as the purchase of property, plant, and equipment, related to expansion to cope with increased expected future sales). ${ }^{1}$

Our analyses are based on regressions of annual earnings (and components of annual earnings) on contemporaneous returns within the fiscal year. This facilitates examination of variation in the earnings/return association during the year. The key to our empirical dissection of ERT is the observation that news at the beginning of the fiscal year reflects expectations for both the current year and future years, while news arriving at the end of the year reflects expectations about future years only. It follows that the portion of ERT that is due to recognition of sales revenue and matched expenses may be estimated via the change in the earnings/return association over the fiscal year, while the earnings/return association at the end of the fiscal year provides an estimate of the expectations element of expenses. Consistent with our prediction, we find a statistically significant decline in the earnings/return coefficient over the fiscal year.

We decompose annual earnings into sales revenue and expenses (i.e., net income minus sales revenue) in order to focus on the expectations element of expenses. ${ }^{2}$ We predict and find that the sales revenue/return coefficient declines from statistically significantly positive at the beginning of the fiscal year to not significantly different from zero at the end of the year. The basis of our prediction is the fact that news in returns at the beginning of the year has the entire year to be captured in sales of the year while news in returns at the end of the year has no time to affect sales of the year.

We predict and find that the expenses/return coefficient increases (i.e., becomes less negative) from the beginning of the year to the end, reflecting expenses that are matched to sales. The portion of ERT due to the expectations element of expenses is captured in the end-of-period expenses/return

\footnotetext{
${ }^{1}$ See, for example, Basu [1997], Ball [2001], Basu [2005], and Ball and Shivakumar [2006].

${ }^{2}$ Expenses have a negative sign in our regressions.
} 
coefficient; this reflects expenses recognized in the current period because of changes in expectations about earnings in future periods. This is the portion of ERT that is predicted to differ across good and bad news partitions. ${ }^{3}$ This expectations element of expenses may reflect management's attempts to affect future earnings (e.g., research and development (R\&D) and advertising), the accounting for the associated expenditures, and GAAP that require recognition of expenses in the current period due to changes in the value of recognized assets of the firm (e.g., restructuring charges and writedowns) because of changes in expectations about future earnings from those assets.

The notion of asymmetric timely loss recognition rests on features of accounting that lead to more immediate recognition of downward changes in value relative to recognition of upward changes in value. Downward revisions in expectations about earnings of future years (associated with negative returns) may, for example, result in immediate recognition of expenses related to the impairment of recognized assets. In contrast, upward revisions in expectations of earnings of future years (associated with positive returns) typically do not result in an increase in the book value of recognized assets (under U.S. GAAP). ${ }^{4}$ This implies that asymmetric timely loss recognition will be manifested in the expectations element of ERT because it reflects the portion of value change related to change in expectations about future earnings that is recognized in contemporaneous earnings. The concept of asymmetric timely loss recognition does not, however, predict that expenses matched to current sales will differ across positive and negative annual return subsamples; but, nevertheless, differences may be observed. Our method permits separate identification of the expectations

\footnotetext{
${ }^{3}$ As an illustration of the relation between value change and the two elements of expenses, consider the effect of the terrorist attacks on the World Trade Center on 9/11/2001 on United Airlines. United's stock price fell from $\$ 30.82$ on $9 / 10 / 2001$ to $\$ 17.10$ when the market reopened on $9 / 17 / 2001$. Expenses matched to sales for the remainder of the third quarter and for the fourth quarter decreased because sales decreased while (nonmatched) expenses related to sales of the future increased dramatically (e.g., there was a $\$ 1.3$ billion charge to earnings associated with the write-off of airplanes and other restructuring charges). Our point is that, if the attack on the World Trade Center had occurred at the beginning of the fiscal year rather than just 113 calendar days before the end of the year, the effect on the matched portion of expenses for 2001 would have been much greater. On the other hand, since the effect of the attack on United Airlines in particular, and the travel industry in general, was expected to have such long-lasting effects, the nonmatched portion most likely would have been very similar whether the attack had occurred on 1/1/2001 or 9/11/2001.

${ }^{4}$ As an illustration of this point, United Airlines wroteoff $\$ 1.3$ million as a result of dramatic downward revisions in expectations of future earnings in the aftermath of the terrorist attacks on 9/11/2001. On the other hand, expenses of InVision Technologies, which was the company that manufactured the explosive detection devices seen in most airports at the time, increased as sales increased for the remainder of the year. But, costs of expansion to cope with expected future sales were capitalized and did not affect expenses for 2001 and the implicit increase in the value of the assets of InVision did not affect reported earnings for 2001 (i.e., the nonmatched expenses were virtually nonexistent).
} 
element of expenses and, hence, it permits a focus on the element at the heart of arguments regarding asymmetric loss recognition.

Our empirical analyses show that the portion of ERT that reflects the sales revenue and matched expense components of earnings is significantly different across positive and negative returns subsamples. That is, the difference in ERT across these subsamples is due to more than just the expectations element of expenses, which is implicitly the element of interest in studies of asymmetric timely loss recognition. This underscores the importance of separately identifying the portion of ERT that is due to the expectations element of expenses rather than inferring this from a comparison of estimates of earnings/annual return coefficients across positive and negative return subsamples.

We conduct further analyses to gain additional insights into the elements of ERT and to ensure the robustness of our findings. First, we note that the earnings/return coefficient may change around the days of the announcements of earnings of the prior year and the announcements of the three quarterly earnings within the fiscal year (i.e., the announcements of earnings of the first three quarters). On these days, the market may be learning about past earnings as well as hearing news about earnings for the rest of the year and for future years. We find that the earnings/return coefficient increases significantly on the earnings announcement days, suggesting that news on these days tends to signal a more transitory effect than on nonearnings announcement days. Importantly, however, including these earnings announcement effects does not significantly change the beginning or end of period coefficient estimates, which highlights the robustness of our main results.

Second, in order to further examine the idea that news arriving at the beginning of the year will have the remainder of the year to be incorporated in earnings of the year, while news arriving at the end of the year will not be incorporated in earnings of the year, we repeat our analyses changing the dependent variables to earnings (and components of earnings) for the current fiscal year $t$ plus the earnings (and components of earnings) for the next year $t+1$ (the independent variables continue to be returns of the fiscal year $t$ ).

As expected, the estimate of the two-year sales revenue/return coefficient at the end of year $t$ is not significantly different from the estimate of the one-year sales revenue/return coefficient at the beginning-of-year $t$ (this is expected because, in both regressions, a whole year remains for recognition of news in sales revenue). Similarly, the estimate of the twoyear expenses/return coefficient at the end of year $t$ is not significantly different from the estimate of the one-year expenses/return coefficient at the beginning-of-year $t$.

Third, in order to ensure that contemporaneous returns are most likely to reflect the events that have affected earnings we analyze a sample of larger firms. This selection of the sample of larger firms is motivated by the early work of Atiase [1985, 1987], Freeman [1987], and Collins, Kothari, 
and Rayburn [1987], which shows that returns capture information relevant to earnings of the fiscal period in a much more timely fashion for large firms than for small firms. The results in Freeman [1987] are particularly pertinent; he shows that, for larger firms, most of the information in earnings is captured in returns by the end of the fiscal year, but, for smaller firms, information in earnings of the year is related to security returns well beyond the year-end.

We compare our main results for the sample of larger firms with the results from an analysis of a set of smaller firms. We observe a higher beginning-of-year sales revenue/return coefficient and a significantly positive end of year sales revenue/return coefficient for the sample of smaller firms; these results (particularly the significantly positive end of year coefficient) suggest that, for smaller firms, some of the information about sales tends to be reflected in returns after the sales have occurred. In other words, we find evidence consistent with Freeman [1987]; sales revenue tends to be recognized earlier than it is reflected in returns (sales revenue is recognized when the transactions occur but the market learns about these sales with a lag). Similarly, for this subsample of observations we find that the estimate of the coefficient relating expenses to returns is more negative at both the beginning of the year and at the end of the year.

Finally, our empirical analyses are based on the assumption of a linear change in the earnings coefficient over the year. We examine the validity of this assumption by regressing sales revenue (and expenses) on each of the 12 monthly returns of the year. The line joining our estimate of the beginning-of-year coefficient and our estimate of the end of year coefficient is within the $95 \%$ confidence interval for each of the monthly coefficient estimates, confirming the validity of our linearity assumption.

The remainder of the paper proceeds as follows. In section 2, we elaborate on the motivation for our paper, we outline the research design, and, we discuss our dissection of ERT. Section 3 briefly describes the sample selection criteria and the sources of data. We present and discuss the results of our analyses in section 4 . We conclude in section 5 .

\section{Motivation and Research Design}

A large body of literature, beginning with Ball and Brown [1968], has examined the properties and economic implications of ERT. Early studies focused on the association between the news component of earnings and abnormal returns (e.g., Beaver, Clarke, and Wright [1979], Hagerman, Zmijewski, and Shah [1984]), while later studies changed the focus to the association between earnings and raw returns (e.g., Beaver, Lambert, and Morse [1980], Easton and Harris [1991], Easton, Harris, and Ohlson [1992], Warfield and Wild [1992], Collins et al. [1994]). With the exception of Beaver, Lambert, and Morse [1980], these studies were motivated by an interest in whether or not the earnings metric and the return metric 
summarized the same underlying information. The mapping between these two variables was of little interest. ${ }^{5}$

Beaver, Lambert, and Ryan [1987] and Basu [1997] shifted the focus of this literature to an examination of the extent to which earnings capture information that has affected firm value in the same fiscal period (i.e., ERT). In these studies, ERT is estimated as the slope coefficient in the following regression of annual earnings on contemporaneous annual stock returns:

$$
E A R N_{j t}=\alpha+\beta^{A N N} \cdot R E T_{j t}+\varepsilon_{j t}
$$

where the dependent variable, $E A R N_{j t}$, is annual earnings for firm $j$ for the fiscal year ending at $t$ deflated by the beginning of fiscal year market capitalization. The explanatory variable, $R E T_{j t}$, is the stock return of firm $j$ for fiscal year $t .{ }^{6}$ Note that $\alpha$ is the regression intercept and $\varepsilon_{j t}$ is the regression disturbance term. The coefficient $\beta^{A N N}$ reflects the portion of the value change in year $t$ that is recognized in period $t$ earnings (i.e., ERT) ${ }^{7}$

Beaver, Lambert, and Morse [1980], in their paper entitled "The Information Content of Security Prices," focused on the slope coefficient from a regression of percentage change in security prices on percentage change in earnings. They showed that this coefficient captures the extent to which earnings changes are transitory or more permanent (subsequently referred to by others as persistence of earnings). ${ }^{8}$ The essence of the model in Beaver, Lambert, and Morse [1980] is that, if earnings are transitory, the price change/earnings change coefficient will be one and, if earnings are permanent, the coefficient will be equal to one plus the inverse of the rate at which future expected earnings are discounted by the market.

In "The Information Content of Security Prices; A Second Look," Beaver, Lambert, and Ryan [1987] reversed the regression, arguing that a regression of percentage change in earnings on percentage change in

\footnotetext{
${ }^{5}$ A related literature that examined the market response to news in earnings was very focused on the mapping from the information in earnings to the market reaction to this information. In this literature, the natural dependent variable is the returns metric. This literature referred to this mapping as the earnings response coefficient (see, Collins and Kothari [1989], Easton and Zmijewski [1989], Kothari and Sloan [1992], Kothari and Zimmerman [1995]). This literature, however, sheds light on a very different question: what is the market response to earnings news? The ERT literature inverts this question and asks: how much of the news that has affected prices is also captured in contemporaneous earnings? The natural dependent variable in this literature is the earnings metric.

${ }^{6}$ Basu [1997] partitions the regression into observations with negative return and those with positive return. The reverse form of this regression, which also restricts the earnings/return coefficient to be the same for all intervals within the fiscal period, was the basis of Beaver, Lambert, and Morse [1980], Easton and Harris [1991], and Easton, Harris, and Ohlson [1992].

${ }^{7}$ The fundamental question addressed in this research design is, what portion of the change in market value is captured in earnings (i.e., change in book value) in the same fiscal period? It follows that earnings appropriately is the dependent variable in this context (see Ball et al. [2013] for an elaboration of this argument).

${ }^{8}$ See, for example, Kormendi and Lipe [1987] and Collins and Kothari [1989].
} 
prices "offers a more intuitive and direct way to assess the information content of security prices, the objective of Beaver et al. (p. 139)." In this specification, the earnings change/price change coefficient will be one if earnings are transitory and less than one if earnings are somewhat persistent; if, for example, the market discount rate is $10 \%$, the earnings change/price change coefficient will be $0.1 / 1.1$ (i.e., $r /(1+r)$ ) if the earnings change is permanent. And a coefficient of 0.2 , for example, is interpreted as: $20 \%$ of the price change is captured in earnings of the period and the remaining price change reflects change in the present value of expected earnings of future periods. ${ }^{9}$

The essence of the model in Beaver, Lambert, and Morse [1980], Beaver, Lambert, and Ryan [1987] is that the price change may reflect information about earnings of the current period or revisions in expectations of earnings of future periods; ERT will be higher if the price change is more related to current period earnings than to future period earnings. Basu [1997] introduced a subtly different perspective. Like Beaver, Lambert, and Ryan [1987], Basu [1997] regressed earnings on returns rather than returns on earnings. Basu [1997] introduced the notion of asymmetric timely loss recognition, explaining differences in earnings/return coefficients across positive and negative return samples as evidence that bad news is incorporated in earnings in a more timely fashion than good news and, hence, the earnings/return coefficient is greater for "loss" firms (i.e., firms with negative return) than "profit" firms. Thus, Basu [1997] introduced a third link in addition to: (1) the link between price changes and current earnings, and (2) the link between price changes and changes in expectations of future earnings. The third link is between changes in expectations of future earnings and expenses incurred in the current period due to the changes in these expectations. It follows that the reduced-form relation between earnings and contemporaneous return (i.e., ERT) captures not only the persistence of the revision in earnings expectations, but also the effect of changes in expectations of future earnings on expenses for the current period.

We argue that there are two distinct accounting concepts, which have fundamentally different effects on ERT, and we estimate these elements of ERT. The first element is a manifestation of the matching principle of accounting in which expenses are recognized in the same period as the related benefits (i.e., sales revenue). The magnitude of this element of ERT is a function of the extent to which the effect of the news is transitory or more permanent in the Beaver, Lambert, and Morse [1980], Beaver, Lambert,

\footnotetext{
${ }^{9}$ An extensive related literature, dating back to Campbell [1991] and Campbell and Shiller [1991], identifies two components of return news: cash flow news and discount rate news. Cash flow news may relate to cash flows of the current period (a transitory effect) or to cash flows of the future (a more persistent effect). Discount rate news affects the rate $(r)$ at which future cash flows are discounted in the current stock price; news that leads to a lower discount rate will lead to a positive price change and lower ERT.
} 
and Ryan [1987] sense; the more transitory the news effect, the higher the ERT. The second element, which we call the expectations element, reflects changes in expectations about future earnings. These changes in expectations lead to recognition of expenses in earnings in the current period; the effect on the ERT depends on the accounting for these expenses.

The magnitude of the effect of the expectations element of ERT depends on the way accounting records expenses in the current period that are a reflection of changes in expectations about future earnings. We use accounting for $\mathrm{R} \& \mathrm{D}$ and accounting for asset write-downs to illustrate this point. $\mathrm{R} \& \mathrm{D}$ is expensed during the period in which the cost is incurred, yet the benefits of the R\&D accrue in the future; the present value of these expected future benefits is incorporated in prices in the current period. That is, the expenses and the price change are recorded contemporaneously. The resultant positive relation between these expenses and the associated positive returns will lead to lower (i.e., more negative) ERT. Asset writedowns are likely associated with bad news about future profitability, which is reflected in negative returns. Unlike $\mathrm{R} \& \mathrm{D}$ expenses, there will be a negative relation between the write-down and the negative returns (i.e., the more negative the returns, the greater the write-down); this will lead to higher ERT. We will return to this point.

Expectations reflected in returns observed at the beginning of the fiscal year will have an entire year to be recognized in sales and matched expenses. In contrast, expectations reflected in returns observed at the end of the fiscal year will have no time remaining to be recognized in sales and matched expenses within the year. Therefore, matched expenses will manifest in an association between annual earnings and contemporaneous returns that is positive at the beginning of the fiscal year, declining to zero at the end of the year. Thus, any association between returns on the last day of the fiscal year and earnings of the year will reflect the expectations element of expenses in ERT.

We develop a research design that utilizes the timing of stock returns within the fiscal year to facilitate the separate empirical identification of the matched expense element and the expectations element of ERT. Specifically, we examine the intrayear change in the earnings/return coefficient via the following regression model:

$$
\begin{gathered}
\qquad \operatorname{EARN}_{j t}=\alpha+\sum_{\tau=0}^{251} \beta_{\tau} \cdot \text { ret }_{j t \tau}+\text { controls }+\varepsilon_{j t}, \\
\text { subject to : } \beta_{\tau}=\beta^{\text {beg }}+\frac{1}{251} \cdot\left(\beta^{\text {end }}-\beta^{b e g}\right) \cdot \tau . \\
\text { This regression is estimated via ordinary least squares as follows: } \\
\qquad A R N_{j t}=\alpha+\beta^{b e g} \cdot \sum_{\tau=0}^{251} r e t_{j t \tau}+\left(\beta^{e n d}-\beta^{b e g}\right) \cdot \sum_{\tau=0}^{251}\left(r e t_{j t \tau} \cdot \frac{\tau}{251}\right) \\
+ \text { controls }+\varepsilon_{j t},
\end{gathered}
$$


where $\sum_{\tau=0}^{251} r e t_{j t \tau}$ is the sum of all daily returns (i.e., the annual return) and $\sum_{\tau=0}^{251}\left(\right.$ ret $\left._{j t \tau} \cdot \frac{\tau}{251}\right)$ is the time-weighted average daily return. ${ }^{10}$ This model reflects three modifications to regression (1).

First, intrayear changes in the earnings/returns relation are captured via the second regressor. Specifically, ret $t_{i \tau}$ is the daily stock return of firm $j$ on trading day $\tau$ within the fiscal year $t$, where $\tau$ is the number of trading days relative to the first day of fiscal year $t .{ }^{11}$ Our selection of daily returns is somewhat arbitrary; similar estimates are obtained with 52 weekly returns or 12 monthly returns. ${ }^{12}$

Second, we constrain the earnings/return coefficient, $\beta_{\tau}$, to follow a linear function of time, $\tau$, within the fiscal year. ${ }^{13}$ There are three reasons why we select a linear constraint: (1) parsimony-in the absence of sound arguments for an alternative form, linearity is usually the first choice; (2) the linear constraint permits estimation of exactly two parameters, $\beta^{\text {beg }}$ and $\beta^{\text {end }}$, allowing us to identify the two elements of expenses in ERT (the matched expense element and the expectations element of expenses)specifically, $\beta^{\text {beg }}\left(\beta^{\text {end }}\right)$ represents the earnings/return coefficient at the beginning (end) of the fiscal year and reflects the portion of the stock returns at the beginning (end) of the year that is recognized in current period earnings; and (3) the assumption of a linear change in the earnings/return coefficient over the year is intuitively appealing-news on the first day of the year has 251 days to be incorporated in earnings, news on the second day has 250 days, ..., etc.

\footnotetext{
${ }^{10}$ To see that this form of the regression captures the constraint $\beta_{\tau}=\beta^{b e g}+$ $\frac{1}{251} \cdot\left(\beta^{\text {end }}-\beta^{b e g}\right) \cdot \tau$, first, expand the summation term to show 252 separate explanatory variables: $E A R N_{j t}=\alpha+\beta_{0} \cdot r t_{j t 0}+\beta_{1} \cdot \operatorname{ret}_{j t 1}+\cdots+\beta_{251} \cdot \operatorname{ret}_{j t 251}+\varepsilon_{j t}$. Then, for each of the 252 beta coefficients (i.e., $\beta_{0}, \beta_{1}, \ldots, \beta_{251}$ ), substitute the expression from the coefficient constraint: $\quad E A R N_{j t}=\alpha+\left[\beta^{b e g}+\frac{1}{251} \cdot\left(\beta^{\text {end }}-\beta^{\text {beg }}\right) \cdot 0\right] \cdot$ ret $_{j t 0}+$ $\left[\beta^{\text {beg }}+\frac{1}{251} \cdot\left(\beta^{\text {end }}-\beta^{\text {beg }}\right) \cdot 1\right] \cdot \operatorname{ret}_{j t 1}+\cdots+\left[\beta^{\text {beg }}+\frac{1}{251} \cdot\left(\beta^{\text {end }}-\beta^{\text {beg }}\right) \cdot 251\right] \cdot \operatorname{ret}_{j t 251}+\varepsilon_{j t}$. Next, rearrange and group similar terms: $E A R N_{j t}=\alpha+\beta^{b e g} \cdot\left(\right.$ ret $_{j t 0}+$ ret $_{j t 1}+\cdots+$ ret $_{j t 250}+$ $\left.r t_{j t 251}\right)+\left(\beta^{\text {end }}-\beta^{b e g}\right) \cdot\left(r t_{j t 0} \cdot \frac{0}{251}+r_{e t}{ }_{j 1} \cdot \frac{1}{251}+\cdots+r_{j t 251} \cdot \frac{251}{251}\right)+\varepsilon_{j t}$. Finally, rewrite using summation notation: $E A R N_{j t}=\alpha+\beta^{b e g} \cdot \sum_{\tau=0}^{251} \operatorname{ret}_{j t \tau}+\left(\beta^{\text {end }}-\beta^{b e g}\right) \cdot \sum_{\tau=0}^{251}$ $\left(\operatorname{ret}_{j t \tau} \cdot \frac{\tau}{251}\right)+\varepsilon_{j t}$.

${ }^{11}$ We use the following daily timing convention: $\tau=251$ is the last trading day of the fiscal year and $\tau=0$ is within two days of the first trading day of the fiscal year. This ensures that all years have 252 days. Daily returns are calculated as the daily price change plus the daily dividend payments divided by the beginning-of-year price, so that the sum of these daily returns is a meaningful construct (i.e., an annual return, which is equal to the annual return metric used in equation (1)). We obtain similar results when we use the log of daily returns as the independent variables.

${ }^{12}$ Either the averaging (across days) occurs in the regression or in the aggregation of daily returns into weekly or monthly returns; our inferences are unchanged if we base our analyses in weekly or monthly specifications, extrapolating the weekly (monthly) estimates of $\beta^{\text {beg }}$ and $\beta^{\text {end }}$ back/forward 2.5 (10) days.

${ }^{13}$ Restricting the coefficients in this manner is similar in spirit to traditional distributed lag models (see Judge et al. [1985]) and mixed data sampling regressions predominantly used in return volatility forecasting models (e.g., Ghysels, Santa-Clara, and Valkanov [2005]).
} 
The difference between the parameter estimates (i.e., $\beta^{\text {beg }}-\beta^{\text {end }}$ ) reflects the change in the earnings/return coefficient over the entire fiscal year. This change captures the sales revenue and matched expense component of ERT; it changes because news at the beginning of the year has the entire year to be incorporated in sales and related expenses of the current year, while news toward the end of the fiscal year has relatively less time (i.e., only a few remaining days) to be recognized as current period sales and matched expenses. The average of the earnings/return coefficient throughout the fiscal year is our estimate of the portion of value change for the fiscal year that is reflected in earnings of the year (i.e., ERT). Expressing the average earnings/return coefficient as $\beta^{\text {end }}+1 / 2 \times\left(\beta^{\text {beg }}-\beta^{\text {end }}\right)$ highlights the separate roles of the sales and matched expense element, $1 / 2 \times\left(\beta^{\text {beg }}-\beta^{\text {end }}\right)$, and the expectations element, $\beta^{\text {end }}$, of ERT.

We include a number of additional variables in regression (2) to control for the expected component of earnings and returns because our fundamental research question focuses on the mapping from the news component of returns to recognition in earnings of unexpected sales and matched expenses and recognition of expenses in the current accounting period that are related to changes in expectations about sales and expenses of future periods. Ball et al. [2013] note that most extant studies following Basu [1997] that relate earnings (as the dependent variable) to raw returns (as the independent variable) include returns as a proxy for news, but do not control for expectations, which is important conceptually. They also provide evidence that removing the expected component of earnings and returns in these regressions avoids the possibility of biased estimates of ERT raised by Patatoukas and Thomas [2011].

We control for the expected portion of earnings (and components of earnings) by adding lagged sales revenue and lagged earnings as additional explanatory variables in regression (2). ${ }^{14}$ We control for the expected portion of returns by adding several variables that have been frequently used as proxies for risk (and therefore proxies for expected returns): log of beginning-of-year market capitalization, log of beginning-of-year share price, beginning-of-year book-to-market ratio, and beginning-of-year debt

\footnotetext{
14 This follows from Ball, Nikolaev, and Kothari [2013], who include lagged earnings as a control for expected earnings. Since our regressions, discussed later, have sales revenue and expenses as dependent variables, we add sales revenue as an additional control. Ball, Nikolaev, and Kothari [2013] observe that the relation between earnings and lagged earnings (and sales and lagged sales) may differ across firms. They suggest two alternative ways of addressing this possibility: (1) permitting the coefficients on lagged earnings (and lagged sales) to vary across industry, or (2) adding firm fixed effects. We use the Barth, Beaver, and Landsman [1998] industry classification to implement the first of these suggestions and find that none of our inferences change under this alternative specification. Our inferences are also unchanged if we add firm fixed effects. We choose to report the results without the addition of firm fixed effects because of the considerable reduction in sample size, particularly when we partition the sample into positive and negative returns and require at least three firm-specific observations in the subsamples.
} 
to equity ratio. ${ }^{15}$ In addition, we include year fixed effects and industry fixed effects based on industry classifications defined in Barth, Beaver, and Landsman [1998].

We decompose annual earnings into sales revenue and expenses in order to focus on expenses where we expect to observe both a matched element and an expectations element. Specifically, we estimate regression (2) after replacing the earnings-dependent variable with sales revenue and with expenses. Analogous to the estimates of the earnings/return coefficients, the average estimate of the sales revenue/return coefficient measures the portion of annual returns that is reflected in sales of the year (i.e., the component of ERT that is due to the recognition of sales revenue). ${ }^{16}$ When annual sales revenue is the dependent variable, we predict (and find) that $\beta^{\text {end }}$ will be equal to zero because news arriving at the end of the year will reflect changes in expectations of future sales rather than sales of the current year.

Matched expenses will manifest in an expenses/return coefficient that increases from a negative value at the beginning of the fiscal year to a value of zero at the end of the year. Thus, these expenses will result in a negative association, on average, between expenses and daily returns. We expect to observe this negative association for both the positive annual return and negative annual return subsamples. We note, however, that the association may differ across the negative return and positive return subsamples; if bad news has a more transitory effect on sales and matched expenses, the expenses/return coefficient will be higher for the negative return subsample. Our empirical analyses are consistent with this notion that the effect of bad news is more transitory.

The arguments in Basu [1997] predict that the expectations element of expenses will differ according to whether the annual returns are positive or negative. When returns are negative, indicating a possible decline in asset values, financial reporting rules tend to accelerate the recognition of expenses (e.g., asset impairments) associated with changes in expectations of sales of future periods, which leads to a positive association between expenses and returns (i.e., the more negative the return, the greater

\footnotetext{
${ }^{15}$ These are the variables suggested by Ball, Nikolaev, and Kothari [2013] as controls for expected returns.

${ }^{16}$ Our predictions (which follow) regarding the magnitude of the sales revenue/return and expenses/return coefficients focus on cash flow news rather than discount rate news. We do not expect discount rate news to have a significant effect on either sales revenue of the current period or on the expenses that are matched to sales of the current period. Discount rate news may lead to an expectations element of expenses (e.g., an impairment loss). There is a possible link between impairments and discount rate news but accounting rules during much of our sample period determined impairment based on undiscounted cash flows and, even if discounted cash flow is used as the basis for impairment testing and subsequent write-downs, the difficulty of (and discretion in) estimating discount rates as a practical matter suggests that discount rate news is likely to have, at most, a second-order effect. Discount rate news will likely be dominated by cash flow news (i.e., news about sales revenue and expenses).
} 
the expenses associated with changed expectations about future earnings). Conversely, financial reporting rules typically do not permit the accelerated recognition of good news about earnings of future periods. This implies that the expectations element of expenses leads to an association between expenses and returns that is not significantly different from zero when annual returns are positive. Our empirical results are consistent with these predictions from the arguments in Basu [1997].

\section{Data and Sample Selection}

To construct our sample, we begin with all firm-year observations from 1972 to 2012 in the Compustat Fundamentals Annual File with observations of net income before extraordinary items (Compustat $I B$ ) and sales revenue (Compustat $S A L E$ ) in the current year and in the preceding year, as well as book value of common equity (Compustat $C E Q$ ), book value of debt (Compustat DLTT plus DLC), price per share (Compustat PRCC_F), and number of shares outstanding (Compustat $\mathrm{CSHO}$ ) at the end of the preceding year. ${ }^{17}$ We remove observations with insufficient data on the daily CRSP files to compute daily stock returns on each of the 252 trading days within the current fiscal year and data required to calculate the market value of equity at the beginning of the fiscal year. We also exclude utility $(4900 \leq$ sic code $\leq 4999)$ and financial $(6000 \leq$ sic code $\leq 6999)$ firms and we exclude observations with a share price less than $\$ 1$ at the beginning of the fiscal year. In order to reduce the influence of outliers on the regression results, each year we remove observations falling in the top or bottom percentile of price-deflated earnings and annual return, in the top percentile of price-deflated sales revenue, and in the bottom percentile of price-deflated expenses. ${ }^{18}$

Our final sample includes 107,404 firm-year observations over the 41 years from 1972 to 2012. In order to ensure that contemporaneous returns are most likely to reflect the events that have led to recognition of sales revenue and expenses of the year (see Freeman [1987]), most of our analyses are based on the subsample of 53,702 observations that have a beginningof-year market value of equity greater than the median beginning-of-year market value of equity for the year; this subsample is more than $97 \%$ of the

\footnotetext{
${ }^{17}$ The start date for our sample is driven by the availability of earnings announcement dates on the quarterly Compustat file.

${ }^{18}$ Removing outliers has a considerable effect on our regression results, particularly in the regressions where the dependent variable is either sales revenue or expenses. This is due to the fact that there are a few (price deflated) expense observations that are very low compared to other observations in the distribution as well as a few (price deflated) sales revenue observations that are very high compared to others in the distribution. The effect of these outliers is not as notable when sales revenue and expenses are combined in the calculation of net income.
} 
T A B L E 1

Descriptive Statistics

\begin{tabular}{|c|c|c|c|c|c|}
\hline Variable & Mean & Std. Dev. & Q1 & Median & Q3 \\
\hline$E A R N_{j t}$ & 0.053 & 0.120 & 0.028 & 0.062 & 0.099 \\
\hline$S A L E S_{j t}$ & 1.967 & 2.431 & 0.576 & 1.206 & 2.415 \\
\hline$E X P_{j t}$ & -1.914 & 2.408 & -2.342 & -1.153 & -0.538 \\
\hline$R E T_{j t}$ & 0.117 & 0.477 & -0.172 & 0.074 & 0.334 \\
\hline$P R C_{j t-1}$ & 29.1 & 31.9 & 15.1 & 23.8 & 36.0 \\
\hline$S I Z E_{j t-1}$ & $3,212.7$ & $14,634.7$ & 175.7 & 527.2 & $1,589.4$ \\
\hline$B T M_{j t-1}$ & 0.593 & 0.512 & 0.288 & 0.478 & 0.768 \\
\hline$L E V E R A G E_{j t-1}$ & 0.469 & 1.093 & 0.044 & 0.208 & 0.526 \\
\hline
\end{tabular}

Descriptive statistics are presented for a sample of 53,702 firm-year observations with a market value of equity above the median in a given year between 1972 and 2012. The mean, standard deviation (Std. Dev.), first quartile (Q1), median, and third quartile (Q3) are reported. $E A R N_{j t}$ is firm $j$ 's annual earnings in fiscal year $t$ scaled by stock price at the beginning of fiscal year $t . S A L E S_{j t}$ is firm $j$ 's annual sales revenue in fisca year $t$ scaled by stock price at the beginning of fiscal year $t . E X P_{j t}$ is firm $j$ 's annual expenses in fiscal year $t$, which is equal to $E A R N_{j t}$ less $S A L E S_{j t} . R E T_{j t}$ is the annual stock return of firm $j$ during fiscal year $t . P R C_{j t-1}$ is firm j's stock price per share on the last day of fiscal year $t-1$. SIZE $E_{j t-1}$ is firm j's market value of equity (in millions) on the last day of fiscal year $t-1 . B T M_{j t-1}$ is firm $j$ 's book value of equity at the end of fiscal year $t-1$ divided by the market value of equity on the last day of fiscal year $t-1$. LEVERAGE $j t-1$ is firm j's book value of current and long-term debt at the end of fiscal year $t-1$ divided by the market value of equity on the last day of fiscal year $t-1$.

market capitalization of the entire sample. ${ }^{19}$ Key characteristics of our sample are shown in table 1 . Later in the paper, we conduct some analyses with the sample of observations of smaller firms and we compare this sample with our main sample at that time.

\section{Results}

\subsection{THE RELATION BETWEEN EARNINGS AND RETURNS}

Table 2 presents the earnings/return coefficients estimated via regression (2). ${ }^{20}$ For the entire sample (reported in the first column), the estimate of the coefficient at the beginning of the fiscal year, $\beta^{b e g}$, is 0.099 $(t$-statistics of 9.78) and the estimate of the coefficient at the end of the fiscal year, $\beta^{\text {end }}$, is 0.038 ( $t$-statistics of 3.47); the latter is the estimate of the expectations element of ERT. The estimate of the sales and matched expense

\footnotetext{
${ }^{19}$ Freeman [1987] shows that, for larger firms, most of the information in earnings is captured in returns by the end of the fiscal year, but, for smaller firms, information in earnings of the year is related to security returns well beyond the year-end. Related work by Atiase [1985, 1987] and Collins, Kothari, and Rayburn [1987] also shows that returns capture information relevant to earnings of the fiscal period in a much more timely fashion for large firms than for small firms.

${ }^{20}$ In all regression specifications in this paper, we include year fixed effects and industry fixed effects based on industry classifications defined in Barth, Beaver, and Landsman [1998]. These industry fixed effects mitigate the effects of systematic differences in the dependent variable (e.g., in the earnings/return regressions, the dependent variable is the ratio of net income to beginning-of-year market capitalization, which is essentially an EP (i.e., earnings-toprice) ratio). The dependent variable is likely much more homogenous at the industry level; our industry-fixed-effects variables are included to mitigate the cross-sectional heterogeneity.
} 
TA B L E 2

Dissection of the Earnings/Return Coefficient

\begin{tabular}{lcccr}
\hline \hline & & \multicolumn{2}{c}{ Sign of Annual Return } & \\
\cline { 3 - 4 } & Full Sample & Positive & Negative & Difference \\
\hline$\beta^{\text {beg }}$ & 0.099 & 0.057 & 0.183 & 0.126 \\
& $(9.78)$ & $(5.23)$ & $(17.06)$ & $(11.04)$ \\
$\beta^{\text {end }}$ & 0.038 & 0.012 & 0.164 & 0.152 \\
& $(3.47)$ & $(1.48)$ & $(15.26)$ & $(16.15)$ \\
$1 / 2\left(\beta^{\text {beg }}-\beta^{\text {end }}\right)$ & 0.030 & 0.023 & 0.009 & -0.013 \\
& $(4.84)$ & $(4.05)$ & $(1.85)$ & $(-2.97)$ \\
$1 / 2\left(\beta^{\text {beg }}+\beta^{\text {end }}\right)$ & 0.068 & 0.034 & 0.174 & 0.139 \\
& $(8.11)$ & $(4.44)$ & $(18.41)$ & $(14.65)$ \\
\hline
\end{tabular}

This table presents the parameter estimates ( $t$-statistics in parentheses) from the following regression model estimated for firm-year observations between 1972 and 2012:

$E A R N_{j t}=\alpha+\sum_{\tau=0}^{251} \beta_{\tau} \cdot$ ret $_{j t \tau}+$ controls $+\varepsilon_{j t}$,

subject to: $\beta_{\tau}=\beta^{\text {beg }}+\frac{1}{251} \cdot\left(\beta^{\text {end }}-\beta^{\text {beg }}\right) \cdot \tau$.

The dependent variable, $E A R N_{j t}$, is firm $j$ 's annual earnings in fiscal year $t$ scaled by stock price at the beginning of fiscal year $t$. Note that ret ${ }_{j t \tau}$ is the stock return of firm $j$ on day $\tau$, which is computed as the change in stock price plus dividends on day $\tau$ scaled by stock price at the beginning of fiscal year $t$, where $\tau$ is the number of trading days relative to the first day of fiscal year $t$. Note that $\beta^{\text {beg }}\left(\beta^{\text {end }}\right)$ is the estimated earnings/return coefficient at the beginning (end) of the fiscal year $t$ and $\alpha$ is the regression intercept (not reported). Additional controls (not reported) include: (1) annual earnings and annual sales revenue in the prior fiscal year scaled by stock price at the beginning of the current fiscal year; (2) the natural logarithm of price per share, the natural logarithm of market value of equity, the ratio of the book value of equity to market value of equity, and the ratio of book value of current and long-term debt to market value of equity measured at the end of the previous fiscal year; and (3) year-fixed-effect and industry-fixed-effect parameters, based on classifications defined in Barth, Beaver, and Landsman [1998]. The first column summarizes parameter estimates for the full sample of 53,702 firm-year observations with a market value of equity above the median for all firms in a given year. The second column presents model parameters estimated for the subsample of 31,233 observations with a positive annual stock return in fiscal year $t\left(R E T_{j t} \geq 0\right)$. The third column presents model parameters estimated for the subsample of 22,469 observations with a negative annual stock return in fiscal year $t\left(R E T_{j t}<0\right)$. The fourth column presents the difference between parameter estimates in the second and third columns. Standard errors are clustered by firm and year (Petersen [2009], Gow, Ormazabal, and Taylor [2010]).

component of ERT, $1 / 2 \times\left(\beta^{\text {beg }}-\beta^{\text {end }}\right)$, is $0.030(t$-statistics of 4.84$)$. The estimate $(0.068)$ of the total ERT (i.e., $\left.1 / 2 \times\left(\beta^{\text {beg }}+\beta^{\text {end }}\right)\right)$, which is the sum of the sales and matched expenses component and the expectations element of expenses, is statistically significantly positive ( $t$-statistics of 8.11). The estimate of the ERT of 0.068 indicates that $6.8 \%$ of the unexpected value change for the fiscal year is, on average, recognized in contemporaneous earnings. More precisely, on average, $6.8 \%$ of the unexpected change in market value is captured in change in book value in the fiscal period in which the change in market value occurs.

The second column of table 2 presents the earnings/return coefficients estimated from regression (2) for the subsample of observations with positive annual return. For this subsample, the coefficient at the beginning of the fiscal year is 0.057 ( $t$-statistics of 5.23) and the coefficient at the end of the fiscal year is 0.012 ( $t$-statistics of 1.48); the latter coefficient is the estimate of the expectations element. The sales and matched expense 
component of ERT for this sample is 0.023 ( $t$-statistics of 4.05). The sum of these elements (i.e., the contribution to ERT) is 0.034 ( $t$-statistics of 4.44).

The third column presents similar coefficient estimates for a subsample of observations with negative annual return. For this subsample, the coefficient at the beginning of the fiscal year is 0.183 ( $t$-statistics of 17.06) and the estimate of the coefficient at the end of the fiscal year, which is the estimate of the expectations element of ERT, is 0.164 ( $t$-statistics of 15.26). The estimate of the sales and matched expenses component of ERT for this sample is 0.009 ( $t$-statistics of 1.85). That is, the expectations element dominates ERT when annual returns are negative.

Finally, the fourth column of table 2 presents the differences between estimates for the negative annual return subsample relative to those for the positive annual return subsample. Consistent with prior studies (e.g., Basu [1997]), we find that the difference in ERT for the negative annual return subsample relative to the positive annual return subsample is significant (0.139 with a $t$-statistics of 14.65$)$, reflecting the overall asymmetry of ERT. As we predicted, this difference is primarily driven by the expectations element (difference of 0.152 , with a $t$-statistics of 16.15 ). However, we also find a significant difference in the sales and matched expense component $(-0.013$, with a $t$-statistics of -2.97$)$; we provide an explanation for this difference when we report the results for the regressions with sales revenue and expenses as the dependent variable. In short, the well-documented asymmetry in ERT across positive and negative annual return subsamples is primarily, but not completely, driven by the expectations element of net income. Since the many studies examining asymmetric timely loss recognition in the spirit of Basu [1997] implicitly seek evidence regarding the expectations element of net income, the observation that the asymmetry is not completely driven by the expectations element underscores the importance of separately identifying this element of ERT. In order to understand the expectations element of net income, we (in the next section) break net income into two components: (1) sales revenue, which has no expectations element, and (2) expenses.

\subsection{THE RELATION BETWEEN SALES REVENUE AND RETURNS AND EXPENSES AND RETURNS}

In this section, we dissect each of the parts of the earnings/return coefficient into a contribution from the sales revenue/return coefficient and a contribution from the expenses/return coefficient obtained by replacing earnings with sales revenue and with expenses in regression (2). Since earnings is equal to sales revenue minus expenses, the estimate of the coefficient in the related earnings/return regressions may be obtained by adding the estimate of the coefficient when sales revenue is the dependent variable and the corresponding estimate of the regression coefficient when expenses is the dependent variable (note that expenses enter the regressions with a negative sign). 
TA B L E 3

Dissection of the Sales Revenue/Return and Expenses/Return Coefficients

\begin{tabular}{|c|c|c|c|c|c|c|}
\hline & \multicolumn{2}{|c|}{$\begin{array}{c}\text { Positive } \\
\text { Annual Return }\end{array}$} & \multicolumn{2}{|c|}{$\begin{array}{c}\text { Negative } \\
\text { Annual Return }\end{array}$} & \multicolumn{2}{|c|}{ Difference } \\
\hline & SALES & $E X P$ & SALES & EXP & SALES & $E X P$ \\
\hline$\beta^{b e g}$ & $\begin{array}{c}0.239 \\
(5.12)\end{array}$ & $\begin{array}{l}-0.182 \\
(-4.74)\end{array}$ & $\begin{array}{r}0.261 \\
(6.63)\end{array}$ & $\begin{array}{l}-0.078 \\
(-1.67)\end{array}$ & $\begin{array}{c}0.022 \\
(0.42)\end{array}$ & $\begin{array}{c}0.104 \\
(2.40)\end{array}$ \\
\hline$\beta^{\text {end }}$ & $\begin{array}{c}0.019 \\
(1.25)\end{array}$ & $\begin{array}{l}-0.007 \\
(-1.08)\end{array}$ & $\begin{array}{l}0.037 \\
(0.96)\end{array}$ & $\begin{array}{c}0.127 \\
(2.95)\end{array}$ & $\begin{array}{c}0.018 \\
(0.06)\end{array}$ & $\begin{array}{c}0.134 \\
(2.12)\end{array}$ \\
\hline $1 / 2\left(\beta^{\text {beg }}-\beta^{\text {end }}\right)$ & $\begin{array}{l}0.110 \\
(3.97)\end{array}$ & $\begin{array}{l}-0.088 \\
(-3.98)\end{array}$ & $\begin{array}{c}0.112 \\
(3.92)\end{array}$ & $\begin{array}{l}-0.103 \\
(-3.95)\end{array}$ & $\begin{array}{c}0.002 \\
(0.36)\end{array}$ & $\begin{array}{l}-0.015 \\
(-0.54)\end{array}$ \\
\hline $1 / 2\left(\beta^{\text {beg }}+\beta^{\text {end }}\right)$ & $\begin{array}{l}0.129 \\
(6.17)\end{array}$ & $\begin{array}{l}-0.095 \\
(-5.69)\end{array}$ & $\begin{array}{c}0.149 \\
(5.64)\end{array}$ & $\begin{array}{c}0.024 \\
(0.66)\end{array}$ & $\begin{array}{c}0.020 \\
(0.09)\end{array}$ & $\begin{array}{r}0.119 \\
(2.56)\end{array}$ \\
\hline
\end{tabular}

This table presents the parameter estimates ( $t$-statistics in parentheses) from the following regression model estimated for firm-year observations between 1972 and 2012:

SALES $_{j t}$ or $\operatorname{EXP}_{j t}=\alpha+\sum_{\tau=0}^{251} \beta_{\tau} \cdot$ ret $_{j t \tau}+$ controls $+\varepsilon_{j t}$,
subject to: $\beta_{\tau}=\beta^{\text {beg }}+\frac{1}{251} \cdot\left(\beta^{\text {end }}-\beta^{\text {beg }}\right) \cdot \tau$.

The dependent variable is either $\operatorname{SALES}_{j t}$ (columns 1 and 3) or $E X P_{j t}$ (columns 2 and 4). Note that $S A L E S_{j t}$ is firm $j$ s annual sales revenue in fiscal year $t$ scaled by stock price at the beginning of fiscal year $t$. Note that $E X P_{j t}$ is firm $j$ 's annual expenses (equal to earnings less sales revenue) in fiscal year $t$ scaled by stock price at the beginning of fiscal year $t$. Note that ret $_{j t \tau}$ is the stock return of firm $j$ on day $\tau$, which is computed as the change in stock price plus dividends on day $\tau$ scaled by stock price at the beginning of fiscal year $t$, where $\tau$ is the number of trading days relative to the first day of fiscal year $t$. Note that $\beta^{\text {beg }}\left(\beta^{\text {end }}\right)$ is the estimated sales/return or expenses/return coefficient at the beginning (end) of fiscal year $t$ and $\alpha$ is the regression intercept (not reported). Additional controls (not reported) include: (1) annual earnings and annual sales revenue in the prior fiscal year scaled by stock price at the beginning of the current fiscal year; (2) the natural logarithm of price per share, the natural logarithm of market value of equity, the ratio of the book value of equity to market value of equity, and the ratio of book value of current and long-term debt to market value of equity measured at the end of the previous fiscal year; and (3) year-fixed-effect and industry-fixed-effect parameters, based on classifications defined in Barth, Beaver, and Landsman [1998]. The first and second columns present model parameters estimated for the subsample of 31,233 observations with a positive annual stock return in fiscal year $t\left(R E T_{j t} \geq 0\right)$. The third and fourth columns present model parameters estimated for the subsample of 22,469 observations with a negative annual stock return in fiscal year $t\left(R E T_{j t}<0\right)$. The fifth column presents the difference between parameter estimates in the first and third columns. The sixth column presents the difference between parameter estimates in the second and fourth columns. Standard errors are clustered by firm and year (Petersen [2009], Gow, Ormazabal, and Taylor [2010]).

Table 3 presents the results from estimation of sales revenue/return coefficients and the expenses/return coefficients estimated via regression (2) with sales revenue (and expenses) replacing earnings as the dependent variable. $^{21}$ The changes in the estimates of the sales revenue/return coefficients over the year are similar for the subsample of observations with positive annual returns and for the subsample with negative annual returns. For the subsample with positive (negative) annual returns (reported in the

\footnotetext{
${ }^{21}$ Again, we include year and industry fixed effects based on industry classifications defined by Barth, Beaver, and Landsman [1998]. These industry fixed effects are particularly important in the regressions based on components of earnings. For example, sales revenue as a proportion of market capitalization likely varies systematically across the sample (retail firms having higher sales than manufacturing firms). The industry fixed effects likely mitigate the effects of these differences.
} 
first (third) column), the estimate of the sales revenue/return coefficient is $0.239(0.261)$ with a $t$-statistics of $5.12(6.63)$ at the beginning of the fiscal year and declines by $0.220(0.224)-0.019(0.037)$ with a $t$-statistics of 1.25 (0.96) at the end of the fiscal year.

The expenses/return coefficients estimated via regression (2) with expenses replacing earnings as the dependent variable are reported in table 3 in columns 2 and 4 . The intrayear patterns of these coefficients differ markedly across the positive and negative annual returns subsamples; this difference explains the marked difference seen in the earnings/return coefficients in table 2. For the subsample of observations with positive annual returns (reported in the second column of table 3), the expenses/return coefficient is -0.182 ( $t$-statistics of -4.74$)$ at the beginning of the fiscal year and increases by 0.175 to -0.007 ( $t$-statistics of -1.08$)$ at the end of the fiscal year. The insignificant expenses/return coefficient at the end of the year suggests that, on average, none of the unexpected value change related to changes in expectations about future sales is recognized in contemporaneous expenses.

When annual returns are negative, we observe a different pattern in the expenses/return coefficient. For this subsample (reported in the fourth column of table 3 ), the expenses/return coefficient is -0.078 ( $t$-statistics of -1.67$)$ at the beginning of the fiscal year and increases by $0.205-0.127$ $(t$-statistics of 2.95) at the end of the fiscal year. The statistically significant increase in the expenses/return coefficient for this subsample reflects a positive association (i.e., the higher (less negative) the returns, the higher the expenses) between matched expenses and returns, which is 0.103 $\left(t\right.$-statistics of 3.95). ${ }^{22}$ However, the estimate of the expectations element of ERT is statistically significantly negative $(-0.127$, with a $t$-statistics of -2.95$)$. In other words, more negative news will, ceteris paribus, imply lower future sales, leading to increased recognition in current earnings of expenses associated with asset impairments and/or restructuring charges. This result is consistent with the concept of asymmetric timely loss recognition, and underscores the main point of Basu [1997]; financial accounting generally requires immediate recognition of asset impairments and restructuring charges when expectations about the future change in such a way that asset values decline, but increases in asset values are generally not, under U.S. GAAP, recognized in the current period.

When the two elements of expenses (matched expenses and the expectations element) are combined into the average expenses/return coefficient, the positive association of the matched expenses and returns is netted against a negative association of the expectations element and returns; when returns are negative, the average expenses/return coefficient is 0.024

\footnotetext{
${ }^{22}$ Expenses enter the analyses reported in the tables with a negative sign. Hence, a negative coefficient estimate reflects a positive correlation between expenses and returns.
} 


\begin{tabular}{llc}
\hline \hline Negative Return Sample & & \\
Sales Revenue & & $\$ 0.149^{* * *}$ \\
Expenses & & \\
Matched & $\$ 0.103^{* * *}$ & \\
Expectations & $-\$ 0.127^{* * *}$ & $-\$ 0.024$ \\
\cline { 2 - 2 } Net Income & & $\$ 0.174^{* * *}$ \\
Positive Return Sample & & \\
Sales Revenue & & \\
Expenses & & \\
Matched & & \\
Expectations & $\$ 0.088^{* * *}$ & \\
Net Income & $\$ 0.007$ & $\$ 0.095^{* * * *}$ \\
\hline
\end{tabular}

FIG. 1.-Dissection of earnings recognition timeliness: summary of estimates of key components. This figure summarizes key coefficients detailed in tables 2 and 3 in the form of a rudimentary income statement. The dollar amounts are the estimated dollar change in the income statement item associated with a $\$ 1$ price change. $* * *$ indicates significance at the 0.001 level.

and is not statistically significant ( $t$-statistics of 0.66 ). Observed in isolation, this result would suggest that expenses are not recorded in a timely manner, which may seem to be inconsistent with the Basu [1997] concept of asymmetric timely loss recognition. However, an examination of the dynamics of the expenses/return coefficient reveals the countervailing influence of matched expenses, which potentially masks the expectations element of interest. In addition, this result reinforces the importance of considering how the earnings/return coefficient changes throughout the fiscal year when formulating and testing hypotheses specifically related to sales and matched expenses and/or the expectations element of expenses.

We summarize the results from tables 2 and 3 in figure 1, where we show how the components of ERT sum together. Beginning with sales revenue: $\$ 1$ less negative price change is associated with $\$ 0.149$ of additional recorded revenue whereas $\$ 1$ more positive price change leads to $\$ 0.129$ of additional recorded revenue. That is, in the Beaver, Lambert, and Morse [1980], Beaver, Lambert, and Ryan [1987] sense, the news effect on sales revenue is more transitory when news is bad. Similarly, matched expenses are also more transitory for the negative price change sample $(\$ 0.103 \mathrm{com}-$ pared with $\$ 0.088$ ). The expectations element of expenses is negative for the negative returns subsample $(-\$ 0.127)$. That is, the less negative the 
returns, the lower the expenses. On the other hand, the expectation element of expenses for the positive returns subsample is small and insignificantly different from zero $(\$ 0.007)$. This evidence regarding the expectations element of expenses focuses the Basu [1997] notion of asymmetric timely loss recognition.

Summing the two elements of expenses for the negative returns sample shows that $\$ 1$ of negative price change is associated with a small and insignificant decrease in expenses $(\$ 0.024)$. On the other hand, summing the two elements of expenses for the positive returns subsample shows that $\$ 1$ of positive price change is associated with $\$ 0.095$ of expenses. Summing each of the components of ERT shows that the ERT for the negative returns subsample is $\$ 0.174$ while the ERT for the positive return subsample is $\$ 0.034$; these estimates correspond to the estimates in a traditional Basu [1997] regression. Our method permits a focus on the expectations element, which is at the core of his arguments about timely loss recognition.

\subsection{CHANGES IN EARNINGS/RETURN COEFFICIENTS AT QUARTERLY EARNINGS ANNOUNCEMENTS}

On earnings announcement days, value change reflects the announcement of quarterly earnings. Since this value change is likely more closely related to earnings of the current period, rather than earnings of future periods, we may expect a different earnings/return coefficient on the days surrounding the earnings announcement dates when compared with the earnings/return coefficient on nonearnings announcement days. Further, it is possible that an observed change in the earnings/return coefficient over the fiscal year may be driven by a higher coefficient mapping from returns to earnings on earnings announcement dates that occur early in the year relative to those later in the fiscal year; in other words, it is possible that our results are driven by a failure to recognize the possibility of changes in the earnings/return coefficients on earnings announcement days. Alternatively, our results (in particular, the observed change in the earnings/return coefficients over the year) may be muted by higher earnings/return coefficients on earnings announcement days later in the fiscal year.

In fact, we expect the change in the earnings/return coefficient on the first earnings announcement of the current fiscal year to be smaller than the change on other earnings announcement days because we have included lagged earnings and lagged sales revenue in our regression specification and the first earnings announcement is primarily an announcement of this earnings and sales revenue information. Also, we expect the change in the earnings/return coefficient around the day of the announcement of earnings for the first quarter to be greater than that around the second quarter's announcement because there remains more of the year for the news in this announcement to affect earnings of the year. Similarly, we expect the change in the earnings/return coefficient around the day of the 
announcement of earnings for the second quarter to be greater than that around the third quarter's earnings announcement.

In order to examine the effect of earnings announcements on our results and inferences, we modify regression (2) to allow the earnings/return coefficient to change on three-day windows centered on each of the four quarterly earnings announcement dates within the current fiscal year. Specifically, we modify the regression (2) as follows:

$$
\begin{aligned}
\operatorname{EARN}_{j t}= & \alpha+\sum_{\tau=0}^{251} \beta_{\tau} \cdot r e t_{j t \tau}+\beta^{l a g} g_{q 4} \cdot r e t_{j t-1}^{q 4}+\beta^{q 1} \cdot r e t_{j t}^{q 1}+\beta^{q 2} \cdot r e t_{j t}^{q 2} \\
& +\beta^{q 3} \cdot r e t_{j t}^{q 3}+\text { controls }+\varepsilon_{j t}, \\
\text { subject to : } \quad \beta_{\tau}= & \beta^{b e g}+\frac{1}{251} \cdot\left(\beta^{e n d}-\beta^{b e g}\right) \cdot \tau,
\end{aligned}
$$

where $r e t_{j t-1}^{q 4}$ is firm $j$ 's stock return during the three-day window centered on the announcement date of fourth quarter earnings of fiscal year $t-1$; $r e t_{j t}^{q 1}, r e t_{j t}^{q 2}$, and $r e t_{j t}^{q 3}$ are firm $j$ 's stock returns during the three-day window centered on the first, second, and third quarter earnings announcement dates, respectively, of the current fiscal year $t$. The estimated parameters, $\beta^{\operatorname{lag}_{-} q^{4}}, \beta^{q 1}, \beta^{q^{2}}$, and $\beta^{q^{3}}$, reflect the incremental change in the earnings/ return coefficient at each of the four quarterly earnings announcements within the fiscal year.

Requiring four earnings announcement dates reduces our sample size to 44,608 observations. We rerun regression (2) for this subsample and find results (see table 4) that are very similar to those for the larger sample reported in table 2; inferences are unchanged. Also, after adding controls for the earnings announcement effects, the estimates of $\beta^{\text {beg }}$ and $\beta^{\text {end }}$ (see table 4) are still very similar to those in table 2 and inferences remain unchanged.

The estimates of the parameters $\beta^{\text {lag }-q^{4}}, \beta^{q 1}, \beta^{q^{2}}$, and $\beta^{q^{3}}$, which capture the incremental change in the earnings/daily return coefficient on earnings announcement days relative to nonearnings announcement days, are positive and statistically significant at conventional levels (see table 4). For example, the estimate of $\beta^{\operatorname{lag}_{-} q 4}$, which captures the incremental shift in the earnings/return coefficient on the first earnings announcement date within the current fiscal year is 0.036 ( $t$-statistics of 2.83) for the sample of positive return observations. These higher earnings/return coefficients on the earnings announcement days imply that the value changes on quarterly earnings announcement dates (potentially a direct result of the revelation of part of earnings for the current year, per se) have a less persistent effect on earnings compared to the portion of value change on non-earnings announcement days.

For the subsample of observations with positive returns, the estimate of the coefficient $\beta^{q 1}$ of 0.077 ( $t$-statistics of 5.61) is greater than the estimate of the coefficient $\beta^{q^{2}}$ of 0.056 ( $t$-statistics of 6.86 ), which, in turn, is greater 
TA B L E 4

Dissection of the Earnings/Return Coefficient Controlling for Earnings Announcement Effects

\begin{tabular}{lcccc}
\hline \hline & $\begin{array}{c}\text { Positive } \\
\text { Annual Return }\end{array}$ & $\begin{array}{c}\text { Negative } \\
\text { Annual Return }\end{array}$ & $\begin{array}{c}\text { Positive } \\
\text { Annual Return }\end{array}$ & $\begin{array}{c}\text { Negative } \\
\text { Annual Return }\end{array}$ \\
\hline$\beta^{\text {beg }}$ & 0.050 & 0.181 & 0.044 & 0.173 \\
$\beta^{\text {end }}$ & $(4.25)$ & $(15.84)$ & $(3.71)$ & $(15.08)$ \\
& 0.008 & 0.163 & 0.006 & 0.160 \\
$\beta^{\text {lag- } q 4}$ & $(0.89)$ & $(12.19)$ & $(0.64)$ & $(10.92)$ \\
& & & 0.036 & 0.039 \\
$\beta^{q 1}$ & & & $(2.83)$ & $(1.81)$ \\
& & & 0.077 & 0.068 \\
$\beta^{q^{2}}$ & & & $(5.61)$ & $(3.75)$ \\
& & & 0.056 & 0.055 \\
$\beta^{q 3}$ & & & $(6.86)$ & $(4.35)$ \\
& & & 0.023 & 0.023 \\
$1 / 2\left(\beta^{\text {beg }}-\beta^{\text {end }}\right)$ & 0.021 & 0.009 & $(3.19)$ & $(1.44)$ \\
& $(2.82)$ & $(1.44)$ & 0.019 & 0.006 \\
$1 / 2\left(\beta^{\text {beg }}+\beta^{\text {end }}\right)$ & 0.029 & 0.172 & $(2.46)$ & $0.96)$ \\
& $(3.77)$ & $(15.79)$ & $(3.40)$ & $(14.65)$ \\
\hline
\end{tabular}

This table presents the parameter estimates ( $t$-statistics in parentheses) from the following regression model estimated for firm-year observations between 1972 and 2012 :

$$
\begin{aligned}
& E A R N_{j t}=\alpha+\sum_{\tau=0}^{251} \beta_{\tau} \cdot r e t_{j t \tau}++\beta^{\text {lag } q 4} \cdot r e t_{j t-1}^{q 4}+\beta^{q 1} \cdot r e t_{j t}^{q 1}+\beta^{q 2} \cdot r e t_{j t}^{q 2}+\beta^{q 3} \cdot r e t_{j t}^{q 3}+\text { controls }^{2}+\varepsilon_{j t}, \\
& \text { subject to: } \beta_{\tau}=\beta^{b e g}+\frac{1}{251} \cdot\left(\beta^{\text {end }}-\beta^{b e g}\right) \cdot \tau .
\end{aligned}
$$

The dependent variable, $E A R N_{j t}$, is firm $j$ 's annual earnings in fiscal year $t$ scaled by stock price at the beginning of fiscal year $t$. Note that $r_{t} t_{j t}$ is the stock return of firm $j$ on day $\tau$, which is computed as the change in stock price plus dividends on day $\tau$ scaled by stock price at the beginning of fiscal year $t$, where $\tau$ is the number of trading days relative to the first day of fiscal year $t$. Note that $r e t_{j t-1}^{q 4}$ is firm $j$ 's stock return during the three-day window centered on the announcement date of fourth quarter earnings of fiscal year $t-1$. Note that $r e t_{j t}^{q 1}, r e t_{j l}^{q^{2}}$, and $r e t_{j t}^{q^{3}}$ are firm $j$ 's stock returns during the three-day window centered on the first, second, and third quarter earnings announcement dates, respectively, of fiscal year $t$. Note that $\beta^{\text {beg }}\left(\beta^{\text {end }}\right)$ is the estimated earnings/return coefficient at the beginning (end) of the fiscal year $t$ and $\alpha$ is the regression intercept (not reported). Additional controls (not reported) include: (1) annual earnings and annual sales revenue in the prior fiscal year scaled by stock price at the beginning of the current fiscal year; (2) the natural logarithm of price per share, the natural logarithm of market value of equity, the ratio of the book value of equity to market value of equity, and the ratio of book value of current and long-term debt to market value of equity measured at the end of the previous fiscal year; and (3) year-fixed-effect and industry-fixed-effect parameters, based on classifications defined in Barth, Beaver, and Landsman [1998] The first and third columns present model parameters estimated for the subsample of 25,962 observations with a positive annual stock return in fiscal year $t\left(R E T_{j t} \geq 0\right)$. The second and fourth columns present model parameters estimated for the subsample of 18,646 observations with a negative annual stock return in fiscal year $t\left(R E T_{j t}<0\right)$. Standard errors are clustered by firm and year (Petersen [2009], Gow, Ormazabal, and Taylor [2010]).

than $\beta^{q^{3}}(0.023$, with a $t$-statistics of 3.19). These declining coefficients are expected; the announcement of the first quarter earnings informs investors about the earnings of the quarter that has passed and about the earnings for the remainder of the year; similar information is provided in the announcement of the second and third quarter earnings but the magnitude of the earnings/daily return coefficients are expected to be less because there is less time remaining for the earnings news to be realized. Similar conclusions can be reached for the subsample of observations with negative annual returns. 


\subsection{OBSERVATIONS WHERE FIRM-SPECIFIC EVENTS AFFECT EARNINGS} BEFORE THEIR EFFECTS ARE INCORPORATED IN STOCK PRICES: THE SAMPLE OF SMALLER FIRMS

Our analyses thus far have been based on a sample of larger firms. We focused on this sample because, a priori, we expected the price of stocks of these firms to incorporate information that affects the firm in a timely manner (i.e., factors that affect sales revenue and expenses become known to the market and affect prices at approximately the same time that they affect sales and expenses). If price change is due to news, which is about future (rather than past) sales, we will observe no relation between returns (news) at the end-of-the-year and sales revenue. This is, indeed, our finding; the end-of-year sales revenue/return coefficient is not significantly different from zero for both the subsample of observations with positive annual returns and for the subsample of observations with negative annual returns. Also, since, under U.S. GAAP, expenses in the current period that are related to expectations of future sales are likely to be small for most firms that have experienced net good news for the year (i.e., for our subsample of larger firms with positive annual return); the finding that the end-of-year expenses/return coefficient is not significantly different from zero for this subsample again supports the notion that, for larger firms, factors that affect expenses become known to the market and affect expenses at the same time.

For firms where the market learns about the factors that affect earnings after the effect is recognized in sales and related expenses, the endof-period sales revenue/return and expenses/return coefficient will be nonzero because return is reflecting sales revenue and related expenses of the past as well as sales and related expenses of the future. This point is made in Atiase [1985, 1987], Freeman [1987], and Collins, Kothari, and Rayburn [1987], who show that returns capture information relevant to earnings of the fiscal period in a much more timely fashion for large firms than for small firms. Each of these papers shows that, for larger firms, most of the information in earnings is captured in returns by the end of the fiscal year, but, for smaller firms, information in earnings of the year is related to security returns well beyond the year-end. None of these papers is suggesting mispricing; rather they suggest that events that lead to recognition of sales revenue and matched expenses may be revealed to the market with a lag. The observation that the market reacts to earnings announcements, which occur sometime after the fiscal period end, is evidence of this phenomenon.

In order to gain more insight into the extent to which events may, for some stocks, affect earnings (i.e., sales revenue and expenses) before their effects are incorporated in stock prices, we compare our results based on the sample of firms with market capitalization above the yearly median with those for a sample of observations with market capitalization below the median. These stocks are quite different. In addition to being much smaller 
TA B L E 5

Dissection of the Sales Revenue/Return and Expenses/Return Coefficients for Small Firms

\begin{tabular}{|c|c|c|c|c|}
\hline & \multicolumn{2}{|c|}{ Positive Annual Return } & \multicolumn{2}{|c|}{ Negative Annual Return } \\
\hline & SALES & EXP & SALES & EXP \\
\hline$\beta^{\text {beg }}$ & $\begin{array}{c}0.380 \\
(7.60)\end{array}$ & $\begin{array}{l}-0.317 \\
(-7.17)\end{array}$ & $\begin{array}{c}0.538 \\
(9.48)\end{array}$ & $\begin{array}{r}-0.293 \\
(-5.49)\end{array}$ \\
\hline$\beta^{\text {end }}$ & $\begin{array}{l}0.145 \\
(2.97)\end{array}$ & $\begin{array}{l}-0.101 \\
(-2.48)\end{array}$ & $\begin{array}{c}0.302 \\
(4.63)\end{array}$ & $\begin{array}{r}-0.004 \\
(-0.07)\end{array}$ \\
\hline $1 / 2\left(\beta^{\text {beg }}-\beta^{\text {end }}\right)$ & $\begin{array}{l}0.118 \\
(3.49)\end{array}$ & $\begin{array}{l}-0.108 \\
(-3.47)\end{array}$ & $\begin{array}{c}0.118 \\
(3.28)\end{array}$ & $\begin{array}{r}-0.144 \\
(-4.72)\end{array}$ \\
\hline $1 / 2\left(\beta^{b e g}+\beta^{e n d}\right)$ & $\begin{array}{c}0.262 \\
(7.26)\end{array}$ & $\begin{array}{l}-0.209 \\
(-7.21)\end{array}$ & $\begin{array}{c}0.420 \\
(8.52)\end{array}$ & $\begin{array}{r}-0.148 \\
(-3.05)\end{array}$ \\
\hline
\end{tabular}

This table presents the parameter estimates ( $t$-statistics in parentheses) from the following regression model estimated for firm-year observations between 1972 and 2012:

$\operatorname{SALES}_{j t}$ or $\operatorname{EXP}_{j t}=\alpha+\sum_{\tau=0}^{251} \beta_{\tau} \cdot$ ret
$j t \tau$

The dependent variable is either $S A L E S_{j t}$ (columns 1 and 3) or $E X P_{j t}$ (columns 2 and 4). Note that $S A L E S_{j t}$ is firm $j$ 's annual sales revenue in fiscal year $t$ scaled by stock price at the beginning of fiscal year $t$. Note that $E X P_{j t}$ is firm $j$ 's annual expenses (equal to earnings less sales revenue) in fiscal year $t$ scaled by stock price at the beginning of fiscal year $t$. Note that $r e t_{j t \tau}$ is the stock return of firm $j$ on day $\tau$, which is computed as the change in stock price plus dividends on day $\tau$ scaled by stock price at the beginning of fiscal year $t$, where $\tau$ is the number of trading days relative to the first day of fiscal year $t$. Note that $\beta^{\text {beg }}\left(\beta^{\text {end }}\right)$ is the estimated earnings/return coefficient at the beginning (end) of the fiscal year $t$ and $\alpha$ is the regression intercept (not reported). Additional controls (not reported) include: (1) annual earnings and annual sales revenue in the prior fiscal year scaled by stock price at the beginning of the current fiscal year; (2) the natural logarithm of price per share, the natural logarithm of market value of equity, the ratio of the book value of equity to market value of equity, and the ratio of book value of current and long-term debt to market value of equity measured at the end of the previous fiscal year; and (3) year-fixed-effect and industry-fixed-effect parameters, based on classifications defined in Barth, Beaver, and Landsman [1998]. The first and second columns present model parameters estimated for the subsample of 26,067 observations with a positive annual stock return in fiscal year $t\left(R E T_{j t} \geq 0\right)$. The third and fourth columns present model parameters estimated for the subsample of 24,712 observations with a negative annual stock return in fiscal year $t\left(R E T_{j t}<0\right)$. Standard errors are clustered by firm and year (Petersen [2009], Gow, Ormazabal, and Taylor [2010]).

(median market capitalization of just $\$ 27.103$ million compared to $\$ 0.527$ billion), the smaller firms' stocks have lower earnings/price ratios (median of 0.040 compared to 0.062 ), higher sales revenue/price ratios (median of 1.903 compared to 1.206 ), higher (more negative) expenses/price ratios (median of -1.905 compared to -1.153 ), lower annual returns (median of $1.6 \%$ compared to $7.4 \%$ ), lower price per share (median of $\$ 5.88 \mathrm{com}$ pared to $\$ 23.80$ ), higher book-to-market ratios (median of 0.730 compared to 0.478 ), and lower leverage (median of 0.243 compared to 0.208 ).

The results for the analyses of the sample of smaller firms are reported in table 5. The estimates of all of the sales revenue/return coefficients are higher for this sample than for the sample of larger firms. Similarly, the estimates of the expenses/return coefficients are lower (more negative). The key difference between the coefficient estimates for this sample of smaller firms compared to the sample of larger firms (see table 3) is that the end-of-year sales revenue/return coefficient is significantly positive for both the positive annual return and for the negative annual return 
subsamples ( 0.145 and 0.302 with $t$-statistics of 2.97 and 4.63$)$. This suggests that, for smaller firms, sales revenue changes precede the incorporation of the effects of factors that affect sales revenue in stock returns. The important point is that this does not appear to be so for the larger firms, which we analyze throughout the paper; for this sample, sales revenue changes are contemporaneous with the incorporation of the effects of factors that affect sales revenue in stock returns.

These results may have profound implications for studies that examine the difference between the earnings/return relation across samples of larger and smaller firms. All extant studies of which we are aware compare the earnings/return coefficients across various samples but the length and timing of the return interval is the same for all samples. Our results suggest that, if (1) the question is: "to what extent are factors that have affected the firm incorporated in earnings of the period, and how does this incorporation differ between observations with positive return and negative return?" and if (2) addressing the question involves a comparison of smaller and larger firms; then, (3) the analysis and the comparison should be based on a longer time period for smaller firms than for larger firms. This observation is also apparent from the results in Freeman [1987], who shows that, for larger firms, there is no significant relation between earnings and returns after the end of the fiscal year but, for smaller firms, this relation continues for several months after the fiscal year-end.

\subsection{INCLUSION OF NEXT YEAR EARNINGS AND COMPONENTS OF EARNINGS IN THE DEPENDENT VARIABLE}

In order to further examine the idea that news at the beginning of the year will have the remainder of the year to be incorporated in earnings of the year while news at the end of the year will not be incorporated in earnings of the year, we repeat our analyses, changing the dependent variables to sales revenue and expenses for the current fiscal year $t$ plus sales revenue and expenses for the next year $t+1$ (the independent variables continue to be returns of the fiscal year $t$ and controls measured at the beginning-of-year $t){ }^{23}$

The results of these analyses are summarized in table 6 . Because requiring two years of sales and expense data changes the composition of our sample, we also include (as panel A) a replication of the analyses in table 3 for this smaller sample. The inferences based on the relation between oneyear earnings (and components of earnings) and returns are unchanged for this smaller sample. As expected (see panel B), the estimates of the two-year sales revenue/return coefficients are significantly higher than the estimates of the one-year sales revenue/return coefficients (see panel A) at

\footnotetext{
${ }^{23}$ These analyses and those in section 4.6 are conducted for the sample of firms covered in the main body of the paper; that is, those with a beginning-of-year market capitalization above the median.
} 
TA B L E 6

Dissection of the Two-Year Sales Revenue/Return and Two-Year Expenses/Return Coefficients

\begin{tabular}{|c|c|c|c|c|}
\hline & \multicolumn{2}{|c|}{ Positive Annual Return } & \multicolumn{2}{|c|}{ Negative Annual Return } \\
\hline & SALES & EXP & SALES & EXP \\
\hline \multicolumn{5}{|c|}{ Panel A: 1-Year Sales Revenue/Return and 1-Year Expense/Return Coefficients } \\
\hline$\beta^{\text {beg }}$ & $\begin{array}{c}0.245 \\
(5.11)\end{array}$ & $\begin{array}{l}-0.187 \\
(-4.66)\end{array}$ & $\begin{array}{c}0.256 \\
(5.89)\end{array}$ & $\begin{array}{l}-0.083 \\
(-1.72)\end{array}$ \\
\hline$\beta^{\text {end }}$ & $\begin{array}{c}0.026 \\
(1.18)\end{array}$ & $\begin{array}{l}-0.012 \\
(-0.71)\end{array}$ & $\begin{array}{c}0.036 \\
(0.92)\end{array}$ & $\begin{array}{r}0.119 \\
(2.54)\end{array}$ \\
\hline $1 / 2\left(\beta^{\text {beg }}-\beta^{\text {end }}\right)$ & $\begin{array}{l}0.104 \\
(3.55)\end{array}$ & $\begin{array}{l}-0.088 \\
(-3.33)\end{array}$ & $\begin{array}{c}0.106 \\
(3.78)\end{array}$ & $\begin{array}{l}-0.101 \\
(-3.36)\end{array}$ \\
\hline $1 / 2\left(\beta^{b e g}+\beta^{\text {end }}\right)$ & $\begin{array}{c}0.136 \\
(5.84)\end{array}$ & $\begin{array}{l}-0.100 \\
(-6.21)\end{array}$ & $\begin{array}{c}0.146 \\
(4.80)\end{array}$ & $\begin{array}{r}0.018 \\
(0.49)\end{array}$ \\
\hline \multicolumn{5}{|c|}{ Panel B: 2-Year Sales Revenue/Return and 2-Year Expense/Return Coefficients } \\
\hline$\beta^{\text {beg }}$ & $\begin{array}{c}0.644 \\
(5.58)\end{array}$ & $\begin{array}{c}-0.540 \\
(-5.55)\end{array}$ & $\begin{array}{c}0.754 \\
(7.47)\end{array}$ & $\begin{array}{c}-0.466 \\
(-4.82)\end{array}$ \\
\hline$\beta^{\text {end }}$ & $\begin{array}{c}0.289 \\
(3.33)\end{array}$ & $\begin{array}{l}-0.204 \\
(-2.94)\end{array}$ & $\begin{array}{c}0.380 \\
(3.00)\end{array}$ & $\begin{array}{r}-0.037 \\
(-0.30)\end{array}$ \\
\hline $1 / 2\left(\beta^{\text {beg }}-\beta^{\text {end }}\right)$ & $\begin{array}{r}0.177 \\
(2.51)\end{array}$ & $\begin{array}{l}-0.168 \\
(-2.72)\end{array}$ & $\begin{array}{c}0.187 \\
(2.66)\end{array}$ & $\begin{array}{l}-0.214 \\
(-3.20)\end{array}$ \\
\hline $1 / 2\left(\beta^{b e g}+\beta^{\text {end }}\right)$ & $\begin{array}{c}0.467 \\
(6.33)\end{array}$ & $\begin{array}{c}-0.372 \\
(-6.46)\end{array}$ & $\begin{array}{r}0.567 \\
(6.28)\end{array}$ & $\begin{array}{r}-0.252 \\
(-2.86)\end{array}$ \\
\hline
\end{tabular}

This table presents the parameter estimates ( $t$-statistics in parentheses) from the following regression model estimated for firm-year observations between 1972 and 2012:

SALES $_{j t}{ }^{2 y r}$ or $\operatorname{EXP}_{j t}{ }^{2 y r}=\alpha+\sum_{\tau=0}^{251} \beta_{\tau} \cdot$ ret $_{j t \tau}+$ controls $+\varepsilon_{j t}$,

subject to: $\beta_{\tau}=\beta^{\text {beg }}+\frac{1}{251} \cdot\left(\beta^{\text {end }}-\beta^{\text {beg }}\right) \cdot \tau$.

The dependent variable is either $\operatorname{SALES}_{j t}{ }^{2 y r}$ (columns 1 and 3) or $\operatorname{EXP}_{j i}{ }^{2 y r}$ (columns 2 and 4). Note that $S A L E S_{j t}{ }^{2 y r}$ is the sum of firms $j$ 's annual sales revenue in fiscal year $t$ and $t+1$ scaled by stock price at the beginning of fiscal year $t$. Note that $\operatorname{EXP}_{j t}{ }^{2 y r}$ is the sum of firm $j$ s annual expenses (equal to earnings less sales revenue) in fiscal year $t$ and $t+1$ scaled by stock price at the beginning of fiscal year $t$. Note that ret $j t \tau$ is the stock return of firm $j$ on day $\tau$, which is computed as the change in stock price plus dividends on day $\tau$ scaled by stock price at the beginning of fiscal year $t$, where $\tau$ is the number of trading days relative to the first day of fiscal year $t$. Note that $\beta^{\text {beg }}\left(\beta^{\text {end }}\right)$ is the estimated earnings/return coefficient at the beginning (end) of the fiscal year $t$ and $\alpha$ is the regression intercept (not reported). Additional controls (not reported) include: (1) annual earnings and annual sales revenue in the prior fiscal year scaled by stock price at the beginning of the current fiscal year; (2) the natural logarithm of price per share, the natural logarithm of market value of equity, the ratio of the book value of equity to market value of equity, and the ratio of book value of current and long-term debt to market value of equity measured at the end of the previous fiscal year; and (3) year-fixed-effect and industry-fixed-effect parameters, based on classifications defined in Barth, Beaver, and Landsman [1998]. The first and second columns present model parameters estimated for the subsample of 27,827 observations with a positive annual stock return in fiscal year $t\left(R E T_{j t} \geq 0\right)$. The third and fourth columns present model parameters estimated for the subsample of 19,629 observations with a negative annual stock return in fiscal year $t\left(R E T_{j t}<0\right)$. Standard errors are clustered by firm and year (Petersen [2009], Gow, Ormazabal, and Taylor [2010]).

both the beginning of the current fiscal year and at the end of the current fiscal year. Similarly, the estimates of the two-year expenses/return coefficients are significantly lower (more negative) than the estimates of the one-year expenses/return coefficients at both the beginning of the current fiscal year and at the end of the current fiscal year. These results reflect the fact that, in these analyses, news at the beginning of the year has two years 
rather than one year to be recognized in sales revenue and expenses and news at the end of the year still has one year to be recognized.

It is also noteworthy that the end-of-year coefficients in the regression with two-year sales revenue (expenses) as the dependent variable are similar to the beginning-of-year coefficients in the regression with one-year sales revenue (expenses) as the dependent variable. This is expected because, in both cases, there remains one year for the news in returns to be recognized in sales revenue (expenses). ${ }^{24}$

\subsection{THE VERACITY OF THE ASSUMPTION THAT THE EARNINGS/RETURN COEFFICIENT CHANGES LINEARLY OVER THE YEAR}

Although the assumption of a linear change in the earnings/return coefficient over the year is intuitively appealing-news on the first day of the year has 251 days to be incorporated in earnings, news on the second day has 250 days, ... , etc.-we examine the validity of this assumption in this section. We do so in two ways.

First, we regress sales revenue (and expenses) on each daily return and we obtain estimates of 252 daily returns coefficients for each of these regressions. That is, we run the following unconstrained regressions:

$$
\begin{aligned}
\text { SALES }_{j t} & =\alpha+\sum_{\tau=0}^{251} \beta_{\tau} \cdot \text { ret }_{j t \tau}+\text { controls }+\varepsilon_{j t} \\
\text { and } \text { EXPENSES }_{j t} & =\alpha+\sum_{\tau=0}^{251} \beta_{\tau} \cdot r t_{j t \tau}+\text { controls }+\varepsilon_{j t} .
\end{aligned}
$$

The estimates of these daily returns coefficients are much more noisy than those in the constrained regression (2) where daily return idiosyncrasies are removed in the calculation of the two independent variables (namely, the sum of the daily returns, $\sum_{\tau=0}^{251} r t_{j t \tau}$, and the time-weighted sum of daily returns $\sum_{\tau=0}^{251}\left(\right.$ ret $\left.\left._{j t \tau} \cdot \frac{\tau}{251}\right)\right) .{ }^{25}$ Nevertheless, they provide an initial sense of the extent to which our assumption of linearity is descriptive of the data.

We plot these daily coefficient estimates in figure 2 for the sample of observations with positive annual returns and in figure 3 for the sample of observations with negative annual returns. The plot provides a sense that

\footnotetext{
${ }^{24}$ In fact, in nontabulated tests, we find that the end-of-year coefficients in the regression with two-year sales revenue (expenses) as the dependent variable are not significantly different from the beginning-of-year coefficients in regressions with one-year sales revenue (expenses) as the dependent variable. The highest $t$-statistics is 1.04 for the difference between the endof-year coefficient for the two-year sales/returns regression (0.380) and the beginning-of-year coefficient for the one-year sales/returns regression (0.256). These $t$-statistics are estimated via restrictions across the two-year and the one-year regressions when they are estimated as seemingly unrelated regressions.

${ }^{25}$ The form of regression (2) is described in detail in footnote 10.
} 


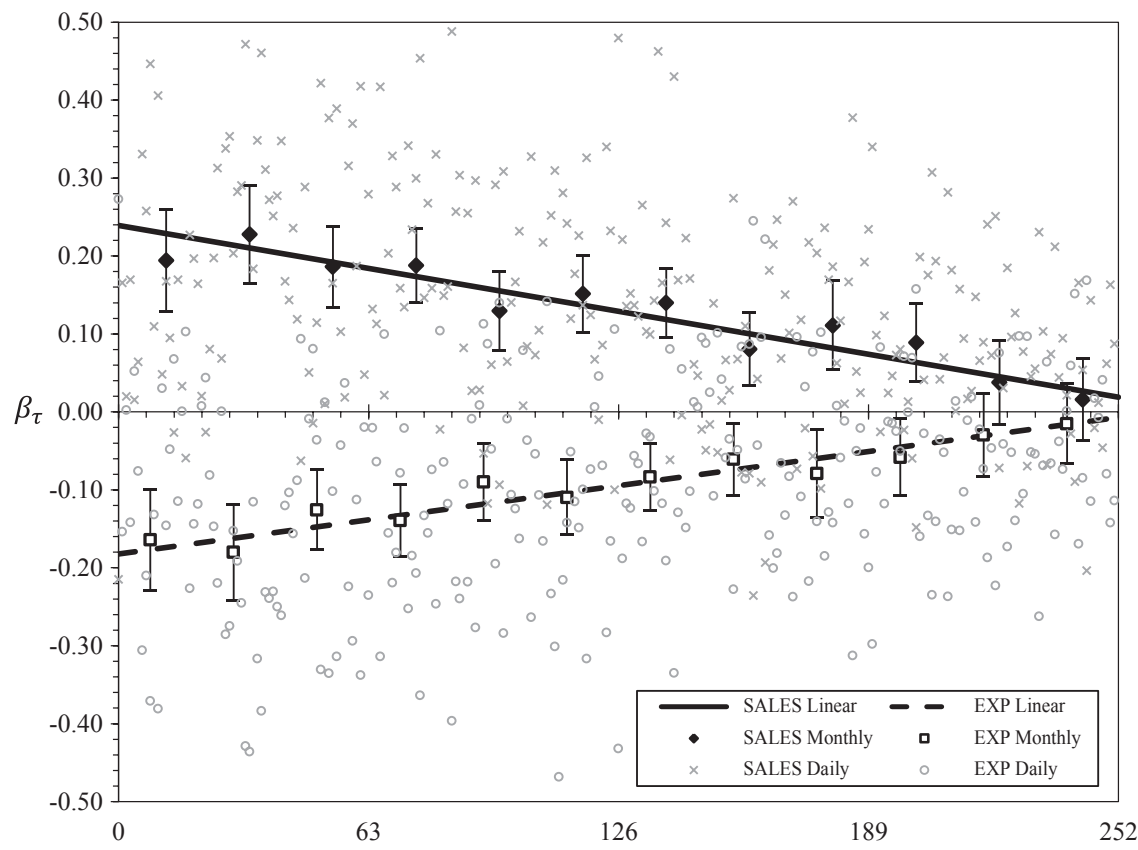

FIG. 2.-Dissection of the sales/return and expenses/return coefficients for a subsample of observations with a positive annual return number of trading days relative to first day of the fiscal year, $\tau$. This figure plots the sales/return and expenses/return coefficient estimates, $\beta_{\tau}$, as a function of the number of trading days relative to the first day of the current fiscal year, $\tau$. Linear coefficients are estimated using the following regression model:

$\begin{aligned} S A L E S_{j t} \text { or } E X_{j t} & =\alpha+\sum_{\tau=0}^{251} \beta_{\tau} \cdot \text { ret }_{j t \tau}+\text { controls }+\varepsilon_{j t}, \\ \text { subject to: } \beta_{\tau} & =\beta^{\text {beg }}+\frac{1}{251} \cdot\left(\beta^{\text {end }}-\beta^{\text {beg }}\right) \cdot \tau .\end{aligned}$

The dependent variable is either $\operatorname{SALES}_{j t}$ (columns 1 and 3) or $\operatorname{EXP}_{j t}$ (columns 2 and 4). Note that $S A L E S_{j t}$ is firm $j$ 's annual sales revenue in fiscal year $t$ scaled by stock price at the beginning of fiscal year $t$. Note that $E X P_{j t}$ is firm $j$ 's annual expenses (equal to earnings less sales revenue) in fiscal year $t$ scaled by stock price at the beginning of fiscal year $t$. Note that $r t_{j t \tau}$ is the daily stock return of firm $j$ on day $\tau$, computed as the change in stock price plus dividends on day $\tau$ scaled by stock price at the beginning of fiscal year $t$, where $\tau$ is the number of trading days relative to the first day of fiscal year $t$. Note that $\beta^{\text {beg }}\left(\beta^{\text {end }}\right)$ is the estimated sales/return or expenses/return coefficient at the beginning (end) of fiscal year $t$ and $\alpha$ is the regression intercept (not reported). Additional controls (not reported) include: (1) annual earnings and annual sales revenue in the prior fiscal year scaled by stock price at the beginning of the current fiscal year; (2) the natural logarithm of price per share, the natural logarithm of market value of equity, the ratio of the book value of equity to market value of equity, and the ratio of book value of current and long-term debt to market value of equity measured at the end of the previous fiscal year; and (3) year-fixed-effect and industry-fixed-effect parameters, based on classifications defined in Barth, Beaver, and Landsman [1998]. Monthly coefficients are estimated using the following regression model:

$S A L E S_{j t}$ or $\operatorname{EXP}_{j t}=\alpha+\sum_{m=1}^{12} \beta_{m} \cdot$ ret $_{j t m}+$ controls $+\varepsilon_{j t}$. 
FIG. 2.-(Continued)

Note that $r e t_{j t m}$ is the stock return of firm $j$ during month $m$, where $m=1(m=12)$ is the first (last) month of fiscal year $t$. Note that $\beta_{m}$ is the estimated sales/return or expenses/return coefficient in month $m$ of fiscal year $t$ and is shown with a plus/minus two-standard-error confidence interval. Daily coefficients are estimated using the following regression model:

$S A L E S_{j t}$ or $\operatorname{EXP}_{j t}=\alpha+\sum_{\tau=0}^{251} \beta_{\tau} \cdot$ ret $_{j t \tau}+$ controls $+\varepsilon_{j t}$.

Note that ret $_{j t \tau}$ is the stock return of firm $j$ during trading day $\tau$, where $\tau=0(\tau=251)$ is the first (last) trading day of fiscal year $t$. Note that $\beta_{\tau}$ is the estimated sales/return or expenses/return coefficient on trading day $\tau$ of fiscal year $t$. All models are separately estimated for a subsample of 31,233 observations with a positive annual stock return in fiscal year $t$ $\left(\sum_{\tau=0}^{251}\right.$ ret $\left._{j t \tau} \geq 0\right)$.

the assumption of linearity may be reasonable; there appears to be a downward slope for the sales revenue/daily return coefficients and an upward slope for the expenses/daily return coefficients.

As a second test of the validity of our linearity assumption, we regress sales revenue and expenses on each of the 12 monthly returns of the year. Unlike regression (2), where the idiosyncrasies in the daily returns are averaged in the variables, $\sum_{\tau=0}^{251} r e t_{j t \tau}$, and $\sum_{\tau=0}^{251}\left(r e t_{j t \tau} \cdot \frac{\tau}{251}\right)$, these idiosyncrasies are averaged in the 12 monthly returns. The estimates of each of these monthly coefficients and the corresponding 95\% confidence intervals around these coefficients are shown in figure 2 for the sample of observations with positive annual returns and in figure 3 for the sample of observations with negative annual returns. We also show the line joining our estimate of the sales/returns coefficient (and the expenses/return coefficient) at the beginning of the year and at the end of the year. Our assumption of linearity appears to be empirically valid: this line is always within the bounds of the confidence intervals around the monthly coefficient estimates. ${ }^{26}$

\section{Summary}

We call the portion of the change in stock price that is recognized in earnings of the period, ERT. We dissect ERT into two components: (1) an element due to sales and matched expenses, and (2) an expectations element. The first component is a manifestation of the matching principle of accounting in which expenses are recognized in the same period as the related benefits (i.e., sales) are recognized. The expectations element reflects

\footnotetext{
${ }^{26}$ Our results are virtually unchanged if, in regression (2), we replace $\sum_{\tau=0}^{251}$ ret ${ }_{j t \tau}$ and $\sum_{\tau=0}^{251}\left(\operatorname{ret}_{j t \tau} \cdot \frac{\tau}{251}\right)$ with $\sum_{\tau=0}^{12}$ mret $_{j t \tau}$ and $\sum_{\tau=0}^{12}\left(\right.$ mret $\left._{j t \tau} \cdot \frac{\tau}{12}\right)$, where mret $_{j t \tau}$ is the monthly return and we extrapolate by half month to estimate the expectations element. We expected this to be so because the key difference between the daily and the monthly specifications is that, in the former, the daily idiosyncrasies are averaged in the regression specification while, in the latter, the same idiosyncrasies are averaged to form a monthly return and then averaged in the regression specification.
} 


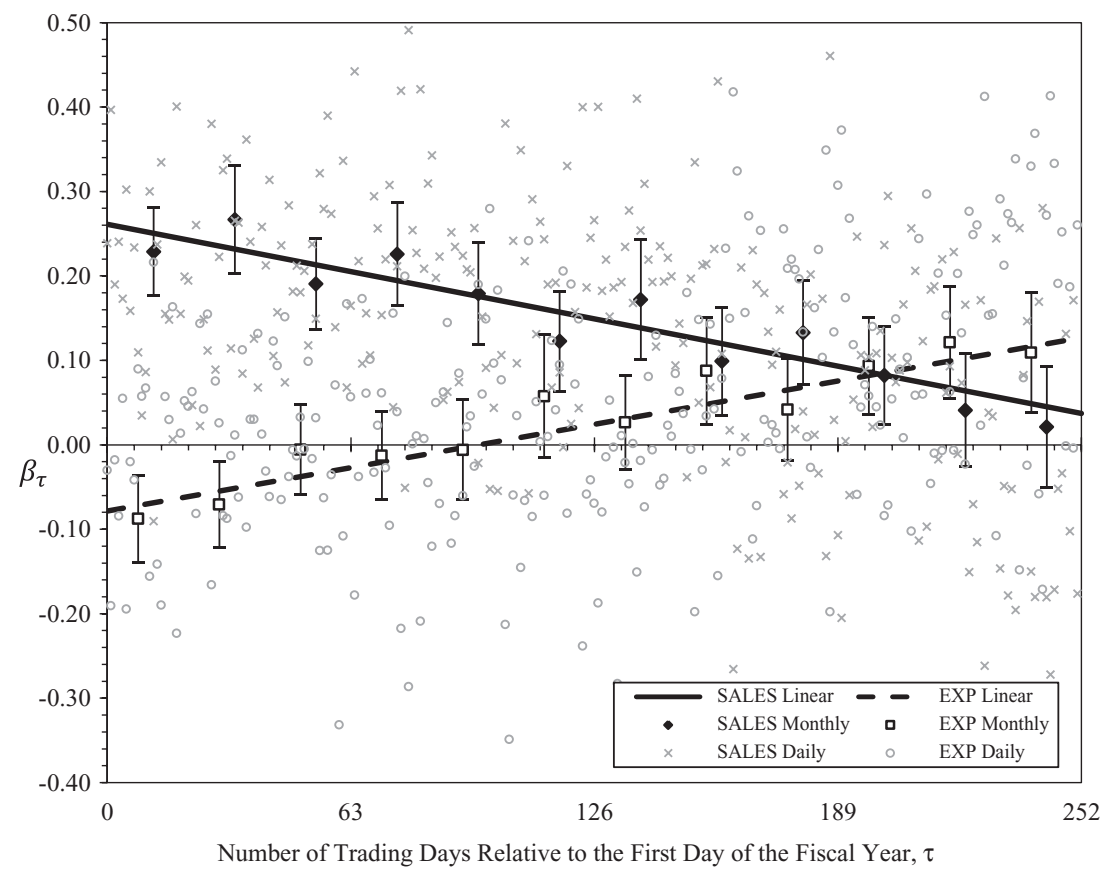

FIG. 3.-Dissection of the sales/return and expenses/return coefficients for a subsample of observations with a negative annual return number of trading days relative to first day of the fiscal year, $\tau$. This figure plots the sales/return and expenses/return coefficient estimates, $\beta_{\tau}$, as a function of the number of trading days relative to the first day of the current fiscal year, $\tau$. Linear coefficients are estimated using the following regression model:

$S A L E S_{j t}$ or $E P_{j t}=\alpha+\sum_{\tau=0}^{251} \beta_{\tau} \cdot$ ret $_{j t \tau}+$ controls $+\varepsilon_{j t}$,

subject to: $\quad \beta_{\tau}=\beta^{\text {beg }}+\frac{1}{251} \cdot\left(\beta^{\text {end }}-\beta^{\text {beg }}\right) \cdot \tau$.

The dependent variable is either $\operatorname{SALES}_{j t}$ (columns 1 and 3) or $E X P_{j t}$ (columns 2 and 4). Note that $S A L E S_{j t}$ is firm $j$ 's annual sales revenue in fiscal year $t$ scaled by stock price at the beginning of fiscal year $t$. Note that $E X P_{j t}$ is firm $j$ 's annual expenses (equal to earnings less sales revenue) in fiscal year $t$ scaled by stock price at the beginning of fiscal year $t$. Note that ret $_{j t \tau}$ is the daily stock return of firm $j$ on day $\tau$, computed as the change in stock price plus dividends on day $\tau$ scaled by stock price at the beginning of fiscal year $t$, where $\tau$ is the number of trading days relative to the first day of fiscal year $t$. Note that $\beta^{\text {beg }}\left(\beta^{\text {end }}\right)$ is the estimated sales/return or expenses/return coefficient at the beginning (end) of fiscal year $t$ and $\alpha$ is the regression intercept (not reported). Additional controls (not reported) include: (1) annual earnings and annual sales revenue in the prior fiscal year scaled by stock price at the beginning of the current fiscal year; (2) the natural logarithm of price per share, the natural logarithm of market value of equity, the ratio of the book value of equity to market value of equity, and the ratio of book value of current and long-term debt to market value of equity measured at the end of the previous fiscal year; and (3) year-fixed-effect and industry-fixed-effect parameters, based on classifications defined in Barth, Beaver, and Landsman [1998]. Monthly coefficients are estimated using the following regression model:

$S A L E S_{j t}$ or $E_{X X}=\alpha+\sum_{m=1}^{12} \beta_{m} \cdot r e t_{j t m}+$ controls $+\varepsilon_{j t}$. 
FIG. 3.-(Continued)

Note that $r e t_{j t m}$ is the stock return of firm $j$ during month $m$, where $m=1(m=12)$ is the first (last) month of fiscal year $t$. Note that $\beta_{m}$ is the estimated sales/return or expenses/return coefficient in month $m$ of fiscal year $t$ and is shown with a plus/minus two-standard-error confidence interval. Daily coefficients are estimated using the following regression model:

$S A L E S_{j t}$ or $\operatorname{EXP}_{j t}=\alpha+\sum_{\tau=0}^{251} \beta_{\tau} \cdot$ ret $_{j t \tau}+$ controls $+\varepsilon_{j t}$.

Note that ret $_{j t \tau}$ is the stock return of firm $j$ during trading day $\tau$, where $\tau=0(\tau=251)$ is the first (last) trading day of fiscal year $t$. Note that $\beta_{\tau}$ is the estimated sales/return or expenses/return coefficient on trading day $\tau$ of fiscal year $t$. All models are separately estimated for a subsample of 22,469 observations with a negative annual stock return in fiscal year $t$ $\left(\sum_{\tau=0}^{251}\right.$ ret $\left._{j t \tau}<0\right)$.

changes in expectations about future earnings and the associated recognition of expenses in earnings in the current period. The change in the earnings/return coefficient over the fiscal year is a manifestation of the sales and matched expense element of ERT. The estimate of this coefficient at the end of the fiscal year is the expectations element of ERT.

As far as we know, the two fundamental precepts of accounting have not previously been identified empirically. The main contribution of our paper is the development and implementation of a method that permits empirical identification of the effects of the accounting for matched expenses and the expectations element of expenses on the mapping from returns to earnings (i.e., ERT). This is important in and of itself in view of the fact that the mapping from returns (and unexpected returns) to earnings (and unexpected earnings) is the most studied relation in market-based accounting research and the two accounting precepts, which we identify empirically, are at the core of financial accounting. The key features of the method could be applied, for example, in the examination of changes in accounting over time. Dichev and Tang [2008] examine changing properties of earnings over time and relate these changing properties to changes in matching of revenues and expenses over time. They do not address the question of the effect of changes in matching on the value relevance of earnings, which is a central question in market-based accounting research. ${ }^{27}$ Our method could be used for such an analyses (value relevance being estimated via the components of ERT).

We show, via an example, that empirical identification of matched expenses and the expectations element of expenses provides additional insights in studies that examine differences in ERT across various scenarios. The example we examine is the comparison of positive annual return and negative annual return subsamples, which is, following Basu [1997], the most widely studied analysis of ERT. We argue that asymmetric timely

\footnotetext{
${ }^{27}$ The method of estimation of matching in Dichev and Tang [2008] differs considerably from ours; they use the estimate of the coefficient on contemporaneous expenses in a regression of revenues on lagged, contemporaneous, and leading expenses.
} 
loss recognition will be manifested in the expectations element of ERT because it reflects the portion of value change recognized in contemporaneous earnings related to changes in expectations about future earnings. The concept of asymmetric timely loss recognition does not, however, predict that the matched expense element of ERT will differ across subsamples of positive annual returns and negative annual returns. Our method permits separation of the expectations element of expenses and, hence, a focus on the element at the heart of arguments regarding asymmetric timely loss recognition.

We find that the matched expense element of ERT is statistically significantly positive for the subsample of observations with positive annual returns but it is not statistically significantly different from zero for the subsamples of negative return observations. The expectations element of ERT is statistically significant for the negative annual return subsample but it is not significantly different from zero for the subsample of observations with positive annual returns. In short, the asymmetry in the ERT is due to both the matched expense element and the expectations element of ERT (although most of the asymmetry is due to the expectations element).

Since our interest is in identifying and understanding the matched expense element and the expectations elements of expenses, we dissect annual earnings into two components: sales revenue and expenses (i.e., earnings minus sales revenue). By so doing, we identify the separate contributions of recognition of sales revenue and expenses to ERT. We show that the sales revenue/return coefficient declines from significantly positive at the beginning of the year to not significantly different from zero at the end of the year. We show that the expenses/return coefficient increases (i.e., becomes less negative) from the beginning of the year to the end, reflecting the matched element of expenses (i.e., the portion of expenses that are matched to sales).

We document a statistically significant difference between the average expenses/return coefficients for the positive annual returns subsample and the negative annual returns subsample. This asymmetry is the combined effect of a positive and statistically significant coefficient for the positive annual returns subsample and a relatively small and not statistically significant coefficient for the negative annual returns subsample. In other words, the observed asymmetry in ERT reflects the fact that expenses are correlated with returns only when news is good. At first glance, this result appears to be surprising and inconsistent with the Basu [1997] notion of asymmetric timely loss recognition. The apparent inconsistency is due to the fact that the expectations element of the expense component of ERT is statistically significantly negative while the matched expense element of the expense component of ERT is statistically significantly positive. The net effect from both elements results in an estimate of the expenses/return coefficient that is, on average, not significantly different from zero for the negative annual returns subsample. These analyses illustrate the usefulness of our 
method in facilitating focus on the element of ERT that is of interest to the researcher-in this example, the expectations element of expenses.

In summary, we present a method, which permits identification of the effects of two fundamental precepts of accounting on ERT, and we provide an example of analyses where the separation of these effects provides new insights.

There is much room for further analyses of intraperiod changes in earnings/return coefficients. Some examples include: (1) consideration of lagged returns (returns of the prior period) and leading returns (returns of the subsequent period) as additional independent variables; (2) comparison of, say, the fourth quarter with the other quarters of the year; and (3) a more detailed analysis of earnings announcement effects. We consider our paper to be the necessary first step to other analyses of components of earnings. This is due to our focus on the fundamental precepts of accounting and our empirical identification of elements of ERT, which reflect the effects of these fundamental precepts.

\section{REFERENCES}

Atiase, R. "Predisclosure Information, Firm Capitalization, and Security Price Behavior Around Earnings Announcements.” Journal of Accounting Research 23 (1985): 21-36.

ATIASE, R. "Market Implications of Predisclosure Information: Size and Exchange Effects." Journal of Accounting Research 25 (1987): 168-76.

BALL, R. "Infrastructure Requirements for an Economically Efficient System of Public Financial Reporting and Disclosure." Brookings-Wharton Papers on Financial Services (2001): 127-69.

BALL, R., AND P. BROWN. "An Empirical Evaluation of Accounting Income Numbers." Journal of Accounting Research 6 (1968): 159-78.

Ball, R.; V. NiKOlaEv; AND S. KothaRI. "On Estimating Conditional Conservatism." The Accounting Review 88 (2013): 755-87.

BALl, R., AND L. SHIVAKUmar. "Role of Accruals in Asymmetrically Timely Gain and Loss Recognition." Journal of Accounting Research 44 (2006): 207-42.

Barth, M.; W. BEAVER; AND W. LANDSMAN. "Relative Valuation Roles of Equity Book Value and Net Income as a Function of Financial Health." Journal of Accounting and Economics 25 (1998): 1-34.

BASU, S. "The Conservatism Principle and the Asymmetric Timeliness of Earnings." Journal of Accounting and Economics 24 (1997): 3-37.

BASU, S. "Discussion—The Effect of Risk on Price Responses to Unexpected Earnings." Journal of Accounting, Auditing and Finance 20 (2005): 173-84.

BeAVER, W.; R. ClaRkE; AND F. WRIGHT. "The Association Between Unsystematic Security Returns and the Magnitude of Earnings Forecast Errors." Journal of Accounting Research 17 (1979): 316-40.

BeAver, W.; R. A. LAmbert; AND D. Morse. "The Information Content of Security Prices." Journal of Accounting and Economics 2 (1980): 3-28.

BEAVER, W.; R. LAMBERT; AND S. RYAN. "The Information Content of Security Prices: A Second Look." Journal of Accounting and Economics 9 (1987): 139-57.

CAMPBELL, J. “A Variance Decomposition for Stock Returns.” Economic Journal 101 (1991): 15779.

CAMPBELl, J., AND R. SHILler. "Yield Spreads and Interest Rate Movements: A Bird's Eye View." Review of Economic Studies 58 (1991): 495-514.

COLLINS, D., AND S. KOTHARI. "An Analysis of Intertemporal and Cross-Sectional Determinants of Earnings Response Coefficients.” Journal of Accounting and Economics 11 (1989): 143-82. 
Collins, D.; S. Kothari; And J. Rayburn. "Firm Size and the Information Content of Prices with Respect to Earnings." Journal of Accounting and Economics 9 (1987): 111-38.

Collins, D.; S. Kothari; J. Shanken; AND R. SloAn. "Lack of Timeliness Versus Noise as Explanations for Low Contemporaneous Return-Earnings Association." Journal of Accounting Eं Economics 18 (1994): 289-324.

DicheV, I., AND V. TANG. "Matching and the Changing Properties of Accounting Earnings over the Last 40 Years." The Accounting Review 83 (2008): 1425-60.

EASTON, P., AND T. HARRIS. "Earnings as an Explanatory Variable for Returns." Journal of Accounting Research 29 (1991): 19-36.

EASTON, P.; T. HARRIS; AND J. OHLSON. "Aggregate Accounting Earnings Can Explain Most of Security Returns: The Case of Long Return Intervals." Journal of Accounting and Economics 15 (1992): 117-42.

EAston, P., AND M. ZMiJEwSKI. "Cross-Sectional Variation in the Stock Market Response to the Announcement of Accounting Earnings." Journal of Accounting and Economics 12 (1989): 117-42.

Freeman, R. "The Association Between Accounting Earnings and Security Returns for Large and Small Firms.” Journal of Accounting and Economics 9 (1987): 195-228.

Hagerman, R.; M. ZMijewski; AND P. SHAH. "The Association Between the Magnitude of Quarterly Earnings Forecast Errors and Risk-Adjusted Stock Returns." Journal of Accounting Research 22 (1984): 526-40.

GHysels, E.; P. SANTA-ClaRA; AND R. VAlKanov. "There Is a Risk-Return Trade-Off After All." Journal of Financial Economics 76 (2005): 509-48.

Gow, I.; G. ORMAZABAl; AND D. TAYloR. "Correcting for Cross-Sectional and Time-Series Dependence in Accounting Research." The Accounting Review 85 (2010): 483-512.

Judge, G.; W. GRIFFITHS; R. Hill; H. LÜTKEPHOL; AND T. LEe. The Theory and Practice of Econometrics. New York: John Wiley \& Sons, 1985.

KORMENDI, R., AND R. LIPE. "Earnings Innovations, Earnings Persistence, and Stock Returns." Journal of Business 60 (1987): 323-45.

KOTHARI, S., AND R. SLOAN. "Information in Prices About Future Earnings." Journal of Accounting E् Economics 15 (1992): 143-71.

KothaRI, S., AND J. Zimmerman. "Price and Return Models." Journal of Accounting and Economics 20 (1995): 155-92.

Patatoukas, P., And J. Thomas. "More Evidence of Bias in the Differential Timeliness Measure of Conditional Conservatism." The Accounting Review 86 (2011): 1765-93.

Petersen, M. A. "Estimating Standard Errors in Finance Panel Data Sets: Comparing Approaches." Review of Financial Studies 22 (2009): 435-80.

WARFIELD, T., AND J. WILD. "Accounting Recognition and the Relevance of Earnings as an Explanatory Variable for Returns.” The Accounting Review 67 (1992): 821-42. 